US Army Corps of Engineers ${ }_{\circledast}$

Engineer Research and

Development Center

ERDC 6.2 Advanced Low-Logistics Water (ALL-H2O)

High-Performance Photocatalytic

Degradation of Model Contaminants with Iron Oxide-Based Colloidal Solutions under Broad-Spectrum Illumination

Emma K. Ambrogi, Emily Asenath-Smith,

and Jonathon A. Brame

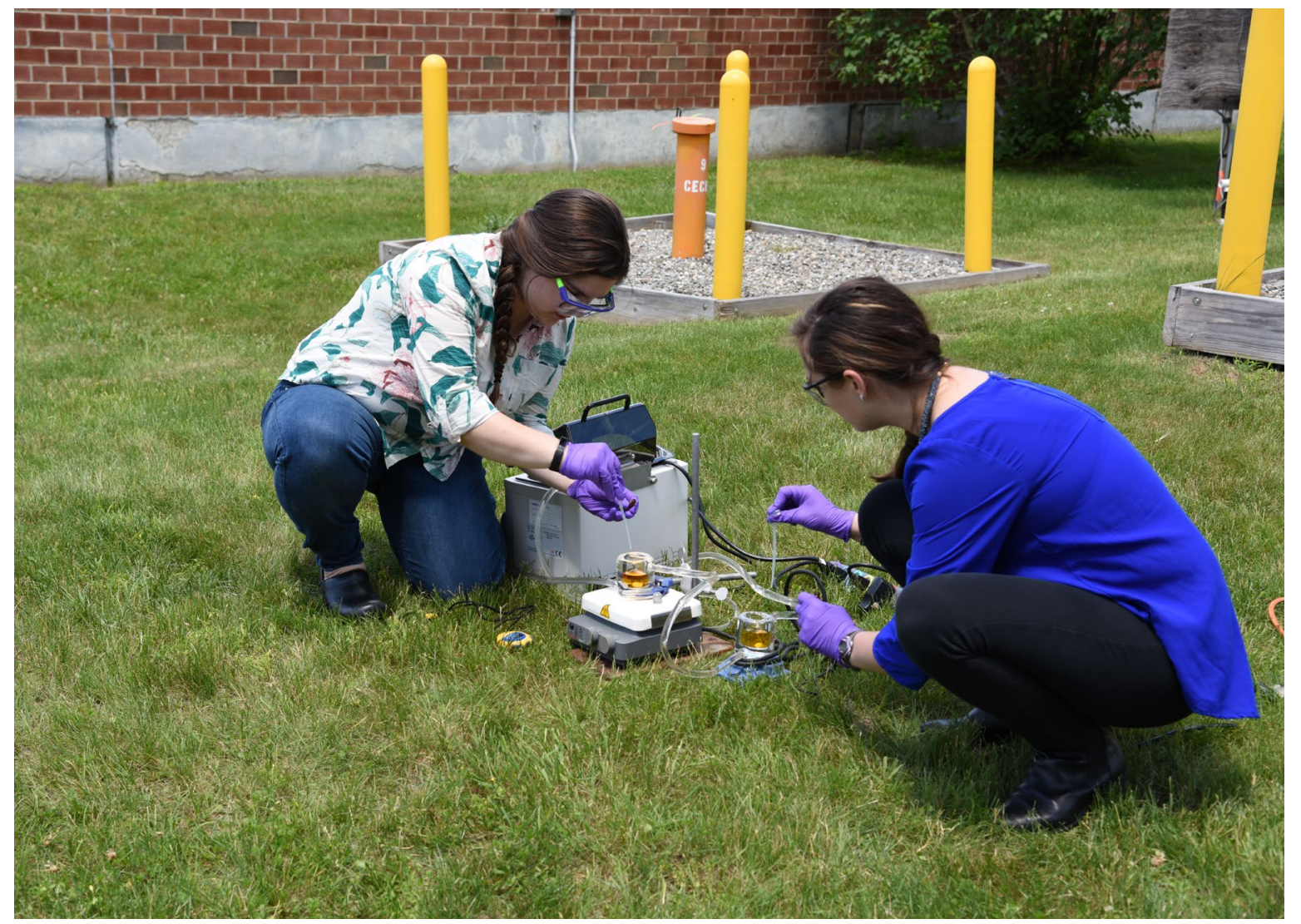


The U.S. Army Engineer Research and Development Center (ERDC) solves the nation's toughest engineering and environmental challenges. ERDC develops innovative solutions in civil and military engineering, geospatial sciences, water resources, and environmental sciences for the Army, the Department of Defense, civilian agencies, and our nation's public good. Find out more at www.erdc.usace.army.mil.

To search for other technical reports published by ERDC, visit the ERDC online library at https://erdclibrary.on.worldcat.org/discovery. 


\section{High-Performance Photocatalytic Degradation of Model Contaminants with Iron Oxide-Based Colloidal Solutions under Broad-Spectrum Illumination}

Emma K. Ambrogi and Emily Asenath-Smith

U.S. Army Engineer Research and Development Center (ERDC)

Cold Regions Research and Engineering Laboratory (CRREL)

72 Lyme Road

Hanover, NH 03755-1290

Jonathon A. Brame

U.S. Army Engineer Research and Development Center (ERDC)

Environmental Laboratory (EL)

Waterways Experiment Station, 3909 Halls Ferry Road

Vicksburg, MS 39180-6199

Final Report

Approved for public release; distribution is unlimited.

Prepared for Headquarters, U.S. Army Corps of Engineers

Washington, DC 20314-1000

Under ERDC 6.2 Advanced Low Logistics Water (ALL-H2O) "Task 6: Catalytic Coatings for Oxidative/Reductive Destruction of Micropolutants," Program Element 622720048, "Industrial Operations Pollution Control Guidance" 


\section{Abstract}

Small molecule contaminants, such as compounds from pharmaceuticals, personal care products, and pesticides, persist through traditional wastewater treatment processes. Heterogeneous photocatalysis with transition metal oxides (TMOs) is an emerging technology for removing these recalcitrant contaminants from wastewater. To leverage this technology, we selectively combined three different TMOs with bandgap energies in different regions of the solar spectrum as a means of harvesting multiple wavelengths of incident radiation to increase the degradation rate of model and real contaminants. Specifically, we combined zincite ( $\mathrm{ZnO}$, ultraviolet active), hematite $\left(\alpha-\mathrm{Fe}_{2} \mathrm{O}_{3}\right.$, visible active), and tenorite $(\mathrm{CuO}$, near-infrared active). The combination of tenorite and hematite (2:1 mass ratio) was the most effective, degrading methyl orange with a rate constant of $40 \pm 1 \mathrm{E}-03 \mathrm{~min}^{-1}$.

When applied to multicontaminant solutions using laboratory illumination, our multispectral photocatalyst degrades real-world contaminants, methyl orange, carbamazepine, and nitrobenzene, with rate constants of $30 \pm 1 \mathrm{E}-03,24 \pm 1 \mathrm{E}-03$, and $6 \pm 1 \mathrm{E}-03 \mathrm{~min}^{-1}$, respectively. In addition, the material degrades contaminants with a greater efficiency under outdoor solar illumination, with Collector Area per Order values of 4.0, 6.1 and 14.5 $\mathrm{kWh} /$ order $/ \mathrm{m}^{3}$, for methyl orange, carbamazepine, and nitrobenzene, respectively. These results demonstrate the effectiveness of this approach to purify water for strategic applications.

DISCLAIMER: The contents of this report are not to be used for advertising, publication, or promotional purposes. Citation of trade names does not constitute an official endorsement or approval of the use of such commercial products. All product names and trademarks cited are the property of their respective owners. The findings of this report are not to be construed as an official Department of the Army position unless so designated by other authorized documents. 


\section{Contents}

Abstract................................................................................................................................. ii

Figures and Tables..............................................................................................................

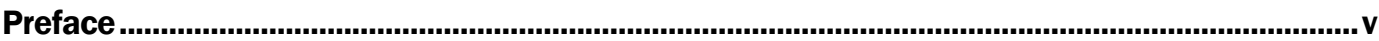

Acronyms and Abbreviations .................................................................................................. vi

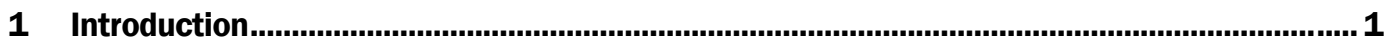

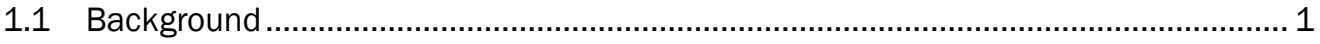

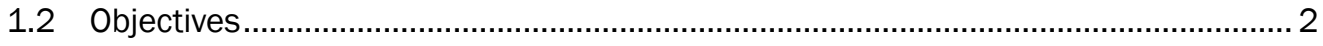

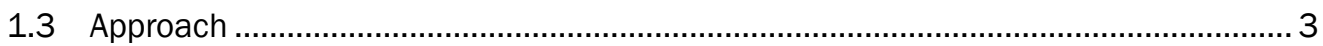

2 Experimental.......................................................................................................................... 4

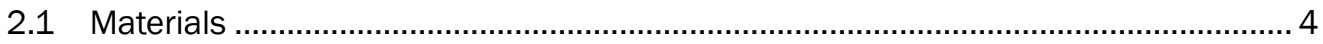

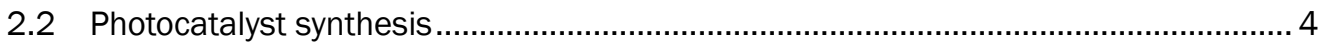

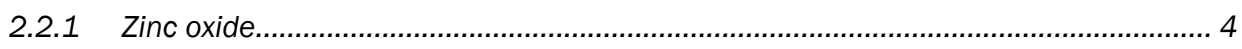

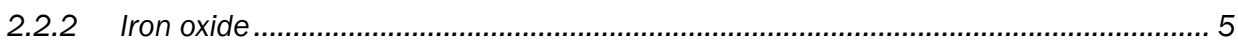

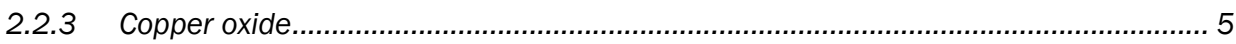

2.3 Photocatalyst materials characterization ....................................................... 5

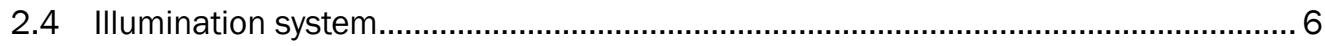

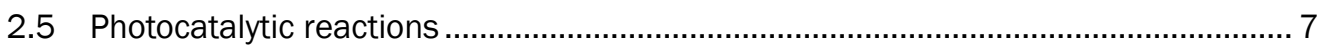

2.6 Chemical analysis ............................................................................................ 7

3 Results and Discussion...................................................................................................... 8

3.1 Overview of photocatalyst properties ............................................................. 8

3.2 Degradation of methyl orange by individual photocatalysts and multispectral materials.................................................................................. 9

3.3 Degradation of multicontaminant mixtures by multispectral materials under laboratory illumination .................................................................................... 11

3.4 Observed degradation products of contaminants .................................................. 12

3.5 Multispectral material as a solar-light-driven photocatalyst .................................... 16

3.6 Electrical Energy per Order of multispectral photocatalysts .................................... 18

3.6.1 Calculating Electrical Energy per Order and Collector Area per Order...................... 18

3.6.2 EE of individual and multispectral photocatalysts under tungsten-halogen

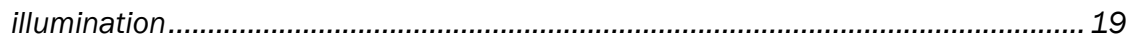

3.6.3 EEO and Aco of multispectral, multicontaminant systems........................................20

4 Conclusions...................................................................................................................22

References..............................................................................................................................23

Appendix A: Mass Spectra of Contaminants and Byproducts.................................................28

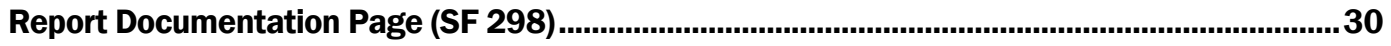




\section{Figures and Tables}

\section{Figures}

1 Laboratory illumination setup.

2 Spectral irradiance of a tungsten-halogen illumination system and outdoor

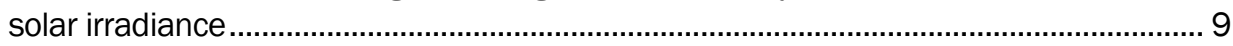

3 Degradation of methyl orange with individual and multispectral photocatalysts under tungsten-halogen illumination.

4 Degradation of the three-contaminant mixture with multispectral material under tungsten-halogen illumination ....................................................................... 12

5 Observed degradation products of methyl orange....................................................... 13

6 Methyl orange degradation products observed with (a) $\mathrm{ZnO},(b) \alpha-\mathrm{Fe}_{2} \mathrm{O}_{3}$, and (c) $\mathrm{CuO}$

7 Methyl orange degradation products observed with (a) MSM-A and (b) MSM-B

8 HPLC-MS chromatograph of multicontaminant degradation with multispectral material

9 Solar spectral irradiance in Hanover, New Hampshire, on 21 June 2018...................... 17

10 Rate constants for degradation of contaminants in outdoor experiments with multispectral photocatalyst and controls

\section{Tables}

1 Materials properties of photocatalysts 8

2 Pseudo-first-order rate constants for degradation of methyl orange with individual photocatalysts and multispectral materials.

3 Pseudo-first-order rate constants for contaminants degraded with MSM-A

4 Chromatographic peaks observed in the degradation of the threecontaminant mixture

$5 E_{E O}$ values for the degradation of methyl orange under tungsten-halogen illumination with individual and multispectral photocatalysts

$6 E_{E O}$ and $A_{C O}$ values for the degradation of the multicontaminant mixture with MSM-A under laboratory and solar illumination. 


\section{Preface}

This study was conducted for the Assistant Secretary of the Army for Acquisition, Logistics, and Technology under U. S. Army Engineer Research and Development Center (ERDC) 6.2 Advanced Low Logistics Water (ALL- $\mathrm{H}_{2} \mathrm{O}$ ) "Task 6: Catalytic Coatings for Oxidative/Reductive Destruction of Micropollutants," Program Element 622720048, "Industrial Operations Pollution Control Guidance.” The technical monitor was Mr. Kurt Kinnevan, Office of the Technical Directors, Environmental Quality and Installations.

The work was performed by the Force Projection and Sustainment Branch of the Research and Engineering Division, U.S. Army Engineer Research and Development Center (ERDC), Cold Regions Research and Engineering Laboratory (CRREL). At the time of publication, Mr. J. D. Horne was Acting Branch Chief and Division Chief. The Deputy Director of ERDC-CRREL was Mr. David B. Ringelberg, and the Director was Dr. Joseph L. Corriveau.

The work was also performed by the Environmental Chemistry Branch of the Environmental Processes and Engineering Division, ERDC Environmental Laboratory (EL). At the time of publication, Ms. Amber Russel was Branch Chief; Mr. Warren Lorentz was Division Chief; and Elizabeth Ferguson was Technical Director for Environmental Quality and Installations. The Acting Deputy Director of ERDC-EL was Dr. Justin Berman, and the Acting Director was Dr. Jack Davis.

COL Teresa A. Schlosser was Commander of ERDC, and Dr. David W. Pittman was the Director. 


\section{Acronyms and Abbreviations}

\begin{tabular}{|c|c|}
\hline $\mathrm{a}-\mathrm{Fe}_{2} \mathrm{O}_{3}$ & Hematite (Iron Oxide) \\
\hline$A_{C O}$ & Collector Area per Order \\
\hline $\mathrm{ALL}-\mathrm{H}_{2} \mathrm{O}$ & Advanced Low Logistics Water \\
\hline BET & Brunauer-Emmett-Teller \\
\hline $\mathrm{CM}$ & Carbamazepine \\
\hline CRREL & U.S. Army Cold Regions Research and Engineering Laboratory \\
\hline $\mathrm{CuO}$ & Tenorite (Copper Oxide) \\
\hline$E_{E O}$ & Electrical Energy per Order \\
\hline ERDC & Engineer Research and Development Center \\
\hline HPLC-MS & High Performance Liquid Chromatography-Mass Spectrometry \\
\hline MO & Methyl Orange \\
\hline MSM-A & Multispectral Material A \\
\hline MSM-B & Multispectral Material B \\
\hline NB & Nitrobenzene \\
\hline PTFE & Polytetrafluoroethylene \\
\hline $\mathrm{TiO} 2$ & Titanium Dioxide \\
\hline TMO & Transition Metal Oxide \\
\hline UVA & Ultraviolet A \\
\hline UV-Vis & Ultraviolet-Visible \\
\hline $\mathrm{ZnO}$ & Zincite (Zinc Oxide) \\
\hline
\end{tabular}




\section{Introduction}

\subsection{Background}

The reuse of wastewater, known as water recycling, has been employed for several decades for nonpotable uses such as agricultural irrigation. In contrast, the reuse of wastewater for potable applications is a developing area that requires higher levels of decontamination and purification than standard wastewater treatment processes (U.S. Environmental Protection Agency 2012). One particular challenge in potable water reuse is the removal of trace amounts of pharmaceuticals, pesticides, and personal care products (Ahmed et al. 2011; Glassmeyer et al. 2017). These contaminants tend to be small, organic molecules that persist through conventional wastewater treatment processes, thus meriting their identification as recalcitrant contaminants (Andreozzi et al. 2003; Le-Minh et al. 2010). Even in trace amounts, these contaminants can negatively affect the environment, including aquatic life (Gorito et al. 2018; Jimenez et al. 2018), and public health (Ternes 2004).

Heterogeneous photocatalysis, where catalyst and reactant are in different phases, is an emerging technology for removing recalcitrant contaminants from wastewater (Robert and Malato 2002; Kabra 2004; Gupta et al. 2012). The cascade of chemical reactions involved in semiconductor photocatalytic processes is initiated by the absorption of a photon, with energy at or above the bandgap of the photocatalytic material, followed by excitation of a valence-band electron to the conduction band of the semiconductor, thereby generating an electron-hole pair (De Lasa et al. 2005). The electron-hole pair can migrate to the material surface, where it reacts with surrounding water and dissolved oxygen to form reactive oxygen species. It is these reactive oxygen species that participate in the redox reactions that lead to the degradation of target contaminants (Nosaka and Nosaka 2013).

As a technology, heterogeneous photocatalysis has seen slow development for industrial applications (Loeb et al. 2019) because of the challenges with incorporating advanced materials into large scale operations. However, heterogeneous photocatalysis remains promising for niche applications (Kwon et al. 2008; Schneider et al. 2014), such as remote operations (Ambrogi et al. 2019) where safety considerations drive the need to accomplish $100 \%$ resuse of water. Largely, the technology's limitations 
stem from low photoconversion efficiencies, which result from poor (visible) light absorption and high electron-hole recombination rates that prevent their participation in surface chemical reactions. In short, for excitation of electrons between the valence and conduction bands of the semiconductor to occur, the energy of the incident photon must at least match the bandgap of the semiconductor (De Lasa et al. 2005). Thus, when a single semiconductor is illuminated with a broad-spectrum light, with significant spectral components below its bandgap, a large amount of the incident radiation is not utilized, resulting in low photoconversion efficiencies.

One approach to increase photoconversion efficiencies is to widen the material's absorption towards the visible region, where greater (solar) spectral irradiance exists (Loeb et al. 2019). Previous studies have attempted many methods to accomplish this (Yu et al. 2009; Kumar and Devi 2011; Yan et al. 2011; Bloh et al. 2012; Ghosh Chaudhuri and Paria 2012; Heiligtag et al. 2014; Asenath-Smith et al. 2016; Méndez-Medrano et al. 2016; Nolan et al. 2016; Yin et al. 2016; Bora and Mewada 2017; Choi et al. 2017; Yan et al. 2017), by doping to shift the band gap and engineering composite-type heterostructures to facilitate charge carrier lifetime. In addition, hierarchical structuring of materials has been shown to increase photocatalytic activity (Asenath-Smith et al. 2015; Chen et al. 2018). These advanced materials show enticing structures and properties; however, most require complicated synthesis procedures, which are difficult to commercialize.

\subsection{Objectives}

The goal of the Advanced Low Logistics Water $\left(\right.$ ALL- $\left.\mathrm{H}_{2} \mathrm{O}\right) 6.2$ work package was to achieve total water recycling for expeditionary military settings to eliminate the need to resupply contingency bases with water. Task 6 of the work package focused on the need to eliminate small-molecule contaminants from wastewater treatment streams so that toxic molecular compounds and their byproducts would not persist and be concentrated by continued reuse of a single water source (Ambrogi et al. 2019). Heterogeneous photocatalyst, as a final polishing step for treated water, could be a viable option to achieve $100 \%$ reuse of water; but higher degradation efficiencies are needed. To enhance contaminant degradation we sought to increase the photocatalytic activity of transition metal oxide (TMO) photocatalysts for scenarios involving broad-spectrum solar radiation sources by combining multiple TMOs with bandgap energies from different ranges of the solar spectrum. To guide our study, we pursued the hypothesis that photocatalytic activity of TMO materials could be enhanced by combining 
TMOs with different bandgap energies to simultaneously harvest multiple wavelengths of light.

\subsection{Approach}

In this work, we report on combinations of three different TMOs with three different band gap energies as a means to harvest multiple wavelengths of incident radiation and to increase the degradation efficiency of small molecule contaminants under broad-spectrum solar illumination. We deliberately selected nontoxic, earth-abundant materials and used low-temperature solution-based synthesis methods (Muñoz-Espi et al. 2007; Vaseem et al. 2008; Lee et al. 2013; Frandsen et al. 2014) to lessen the environmental impact of the photocatalytic reactor. Lastly, we chose to target materials that were $100 \mathrm{~nm}$ or larger in an effort to facilitate amenability to filtration in future applications in water treatment trains. Specifically, we report on the combination of three photocatalysts: ultraviolet A (UVA) active zincite (zinc oxide), $\mathrm{ZnO}$ (Lu et al. 2008; Ma et al. 2011); visible active hematite (iron oxide), $\alpha-\mathrm{Fe}_{2} \mathrm{O}_{3}$ (Zhou and Wong 2008; Cha et al. 2011); and near-infrared active tenorite (copper oxide), $\mathrm{CuO}$ (Li et al. 2011; Shaabani et al. 2014). By combining these photocatalytic materials, we achieved degradation rates that exceeded the sum of the individual photocatalysts, implying that there is a synergistic interaction between the various photocatalysts related to their associated reactive oxygen species. This synergy between these photocatalysts allowed for effective degradation of model contaminants methyl orange (MO), carbamazepine (CM), and nitrobenzene (NB). 


\section{Experimental}

\subsection{Materials}

All reagents were used as received without further purification:

- zinc nitrate hexahydrate (purum p.a. crystallized, $\geq 99.0 \%$, Sigma Aldrich)

- hexamethylenetetramine (ACS Reagent, $\geq 99.0 \%$, Sigma Aldrich)

- iron(III) chloride hexahydrate (puriss. p.a., Reag. Ph. Eur., $\geq 99 \%$, Sigma Aldrich)

- sodium phosphate monobasic dihydrate (purum p.a., crystallized, $\geq 99.0 \%$, Sigma Aldrich)

- copper(II) nitrate trihydrate (purum p.a. 98\%-103\%, Sigma Aldrich)

- sodium hydroxide (Certified ACS Reagent, Fisher Scientific)

- hydrogen peroxide (30\%, Fisher Scientific)

- MO (Reag, Ph. Eur., Sigma Aldrich)

- $\mathrm{CM}$ (98\%, Alfa Aesar)

- NB (ACS Reagent Grade, $\geq 99 \%$, Sigma Aldrich)

- titanium dioxide $\left(\mathrm{TiO}_{2} ; \mathrm{P}_{25}\right.$, Sigma-Aldrich).

All solutions were made using $12 \mathrm{M} \Omega^{*}$ MilliQ water.

\subsection{Photocatalyst synthesis}

\subsubsection{Zinc oxide}

Zinc oxide $(\mathrm{ZnO})$ particles were synthesized hydrothermally in aqueous solution according to procedures described in Muñoz-Espi et al. 2007. In a typical synthesis, $95 \mathrm{~mL}$ of $0.016 \mathrm{M}$ zinc nitrate hexahydrate was stirred and heated to $100^{\circ} \mathrm{C}$. Hexamethylenetetramine (0.210 $\mathrm{g}$ of $\left.0.00150 \mathrm{~mol}\right)$ was dissolved in $5 \mathrm{~mL}$ of water and added to the reaction mixture. The reaction mixture was heated while stirring for $90 \mathrm{~min}$ and then cooled and filtered (high purity, fine grade, ashless filter, Whatman) under vacuum with a Buchner funnel to collect precipitated $\mathrm{ZnO}$ particles. $\mathrm{ZnO}$ particles were washed with water $(2 \times)$ and ethanol $(1 \times)$ and then dried under vacuum.

\footnotetext{
* For a full list of the spelled-out forms of the units of measure used in this document, please refer to U.S. Government Publishing Office Style Manual, 31st ed. (Washington, DC: U.S Government Publishing Office, 2016), 248-252, https://www.govinfo.gov/content/pkg/GPO-STYLEMANUAL-2016/pdf/GPO-STYLEMANUAL-2016.pdf.
} 


\subsubsection{Iron oxide}

Spindle-type hematite $\left(\alpha-\mathrm{Fe}_{2} \mathrm{O}_{3}\right)$ particles were prepared as described by Fransden et al. (2014). Iron(III) chloride hexahydrate (1.08 g of $0.020 \mathrm{M}$ ) was dissolved in a solution of monosodium phosphate $(200 \mathrm{~mL}$ of o.o mM). The solution was placed in a screw-top glass media bottle and aged at $100^{\circ} \mathrm{C}$ for 2 weeks in a laboratory oven. Following aging, the solution was cooled, and then precipitated $\alpha-\mathrm{Fe}_{2} \mathrm{O}_{3}$ particles were collected via vacuum filtration using a track-etched membrane (Nucleopore, $0.2 \mu \mathrm{m}$, Whatman) over a Buchner funnel. Particles were washed with water and ethanol, then dried under vacuum.

\subsubsection{Copper oxide}

Copper oxide $(\mathrm{CuO})$ particles were synthesized hydrothermally in aqueous solution using procedures previously reported in Vaseem (2008) and Li et al. (2011). In a typical synthesis, $50 \mathrm{~mL}$ of $0.1 \mathrm{M}$ copper nitrate trihydrate were combined with $50 \mathrm{~mL}$ of $0.1 \mathrm{M}$ hexamethylenetetramine and stirred while heating to $100^{\circ} \mathrm{C}$. Once heated, $8 \mathrm{~mL}$ of $1 \mathrm{M} \mathrm{NaOH}$ were added to the reaction mixture; heating was continued for an additional $90 \mathrm{~min}$. After cooling at room temperature, the precipitated $\mathrm{CuO}$ particles were collected via vacuum filtration, as described for $\mathrm{ZnO}$ above, rinsed with water $(2 \times)$ and ethanol $(1 \times)$, and dried under vacuum.

\subsection{Photocatalyst materials characterization}

The TMO photocatalyst samples were dispersed in ethanol and drop-cast onto silicon wafers for imaging in a scanning electron microscope (Model 630 , FEI, USA), which was operating at $5 \mathrm{kV}$ and a pressure of $0.1-$ 0.5 mbar. The specific surface area of the TMO materials was measured by nitrogen adsorption with a NOVAtouch Surface Area and Pore Size Analyzer (Quantachrome Instruments, USA) operating at $350.5^{\circ} \mathrm{C}$. Samples were degassed under vacuum at $300^{\circ} \mathrm{C}$ for 180 min before measurement. Powder X-ray diffraction was performed with an X'pert PRO diffractometer (Malvern PANalytical, UK) equipped with a cobalt source running at 45 $\mathrm{kV}$ and $40 \mathrm{~mA}$. The bandgap of the TMO materials was determined from the Tauc plots of the Kubelka-Munk functions of diffuse reflectance spectra collected with a fiber spectrometer (Flame-S-UV-VIS-ES, Ocean Optics, USA). Diffuse reflectance spectra were collected from compacted TMO powders using a reflection probe (QR-400-7-SR, Ocean Optics, 
USA). A balanced deuterium tungsten lamp (DH-2000-BAL, Ocean Optics, USA) was used as the broadband illumination source.

\subsection{Illumination system}

A broad-spectrum illumination system based on two tungsten-halogen lamps (ASI Illuminator, $50 \mathrm{~W}$ each) was used to supply light to the photocatalytic experiments. The illuminators were placed on tripods and pointed at a stir plate on which a glass jacketed beaker was placed. The lamps were positioned $35 \mathrm{~cm}$ above the stir plate and $30 \mathrm{~cm}$ apart from each other. Lamps were angled such that beams were directed at the center of the stir plate and were allowed to warm up for at least 5 min before each reaction. Figure 1 shows a diagram of the photocatalytic illumination setup. The incident spectral irradiance of the laboratory illumination system and of the outdoor solar irradiance present during outdoor experiments was measured with a calibrated spectroradiometer (Model HR1024i, range 340-2500 nm, Spectra Vista Corp., USA) and a calibrated diffuse reflectance target (Spectralon, Labsphere, USA). Asenath-Smith et al. (2019) previously detailed characterization of the incident irradiation of the illumination system.

Figure 1. Laboratory illumination setup.

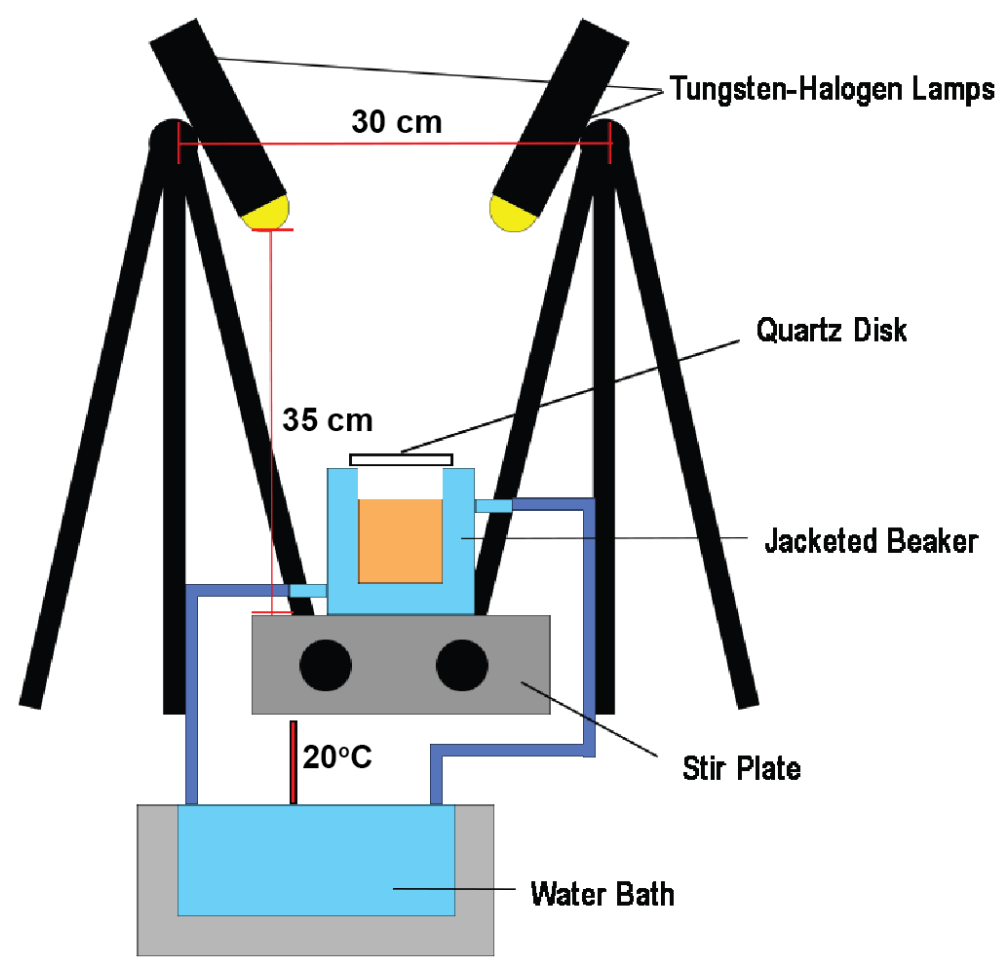




\subsection{Photocatalytic reactions}

In a typical photocatalytic reaction with a single contaminant (MO) and single photocatalyst, an aqueous solution ( $40 \mathrm{~mL}$ of $25 \mathrm{mM}$ ) was placed in a glass jacketed beaker. Then $30 \mathrm{mg}$ of the photocatalyst was added to the solution. A quartz disk was placed on top of the beaker. Water from a water bath maintained at $20^{\circ} \mathrm{C}$ was pumped through the cooling layer of the beaker. The mixture of photocatalyst and contaminant was stirred in the dark for $15 \mathrm{~min}$ (protected from any light exposure), after which time a 1.5 $\mathrm{mL}$ aliquot was withdrawn ( $t=0 \mathrm{~min}$ point). Then $100 \mu \mathrm{L}$ of hydrogen peroxide was immediately added, and the beaker was illuminated. Aliquots (1.5 $\mathrm{mL}$ ) were taken every $15 \mathrm{~min}$ for $1 \mathrm{hr}$ ( 4 aliquots) for analysis by ultravioletvisible (UV-Vis) spectroscopy and high performance liquid chromatography-mass spectrometry (HPLC-MS). Aliquots were filtered through 0.20 $\mu \mathrm{m}$ filters (Millex PTFE [polytetrafluoroethylene]) to remove the photocatalyst and then placed in a quartz cuvette (for UV-Vis analysis) or vial (for HPLC-MS). Experiments with multispectral material A (MSM-A) used $15 \mathrm{mg}$ $\mathrm{a}-\mathrm{Fe}_{2} \mathrm{O}_{3}$ and $7.5 \mathrm{mg} \mathrm{CuO}$. Experiments with multispectral material B (MSMB) used $15 \mathrm{mg} \alpha-\mathrm{Fe}_{2} \mathrm{O}_{3}$ and $7.5 \mathrm{mg}$ of each $\mathrm{CuO}$ and $\mathrm{ZnO}$. Multicontaminant experiments utilized $40 \mathrm{~mL}$ of a solution of $\mathrm{MO}(25 \mu \mathrm{M}), \mathrm{CM}(25 \mu \mathrm{M})$, and NB $(50 \mu \mathrm{M})$. Multispectral material and multicontaminant experiments used the same illumination and sampling procedures as single contaminant, single photocatalyst experiments. All experiments were carried out in triplicate.

\subsection{Chemical analysis}

A Genesys 10S UV-Vis spectrophotometer (ThermoFisher, USA) was used for spectroscopic analysis. Samples in $1 \times 1 \times 4.5 \mathrm{~cm}$ quartz cuvettes were scanned from 650 to $200 \mathrm{~nm}$ at an interval of $1 \mathrm{~nm}$. Mixtures of contaminants and reagents were analyzed with HPLC-MS (Accela, ThermoFisher, USA) equipped with a C18 column (Zorbax Eclipse Plus $4.5 \times 150 \mathrm{~mm}$, $5 \mu \mathrm{m}$ ) with electrospray ionization. The methodology for HPLC was as follows: 70/30 aqueous $10 \mathrm{mM}$ ammonium acetate / acetonitrile for 3 minutes, ramping from $70 / 30$ to $50 / 50$ ammonium acetate / acetonitrile from minute 3 to 7 , and holding at that concentration from minute 7 to 12 . The flow rate was $600 \mu \mathrm{L} / \mathrm{min}$. Peaks were fit to Gaussian distributions and integrated to find peak areas; relative concentrations were calculated by the ratio of initial to final peak areas. For MS analysis, the probe voltage was 3 $\mathrm{kV}$, the cone voltage was $75 \mathrm{~V}$, the $\mathrm{N} 2$ flow rate was $12 \mathrm{~L} / \mathrm{min}$, and the nebulizing gas pressure was $75 \mathrm{psi}$. The electrospray ionization probe oscillated between negative and positive ion mode every $1 \mathrm{sec}$. 


\section{Results and Discussion}

\subsection{Overview of photocatalyst properties}

We used a variety of methods to rigorously characterized the photocatalysts used in this study (reported elsewhere reference pending). ${ }^{*}$ Table 1 briefly summarizes the photocatalyst properties. Wavelengths listed refer to the wavelengths of light corresponding to the material band gaps, which were obtained using diffuse reflectance spectroscopy. The specific surface area of the photocatalyst particles was obtained using nitrogen adsorption by the Brunauer-Emmett-Teller (BET) method, and the particle dimensions were obtained using scanning electron microscopy. To facilitate the transition of this bench-scale research to applications, we specifically targeted materials that (1) were made from earth-abundant elements (such as iron, copper, and zinc) and (2) were made to be greater than $100 \mathrm{~nm}$ in size. $\mathrm{TiO}_{2}$ is the most widely used photocatalyst in commercial applications, so we used P25, a commercially available formulation of $\mathrm{TiO}_{2}$, as a control. Note that the size of the P25 particles listed in Table 1 was determined with laser scattering analysis rather than scanning electron microscopy. See Section 2.3 for details of the photocatalyst characterization experiment.

Table 1. Materials properties of photocatalysts.

\begin{tabular}{|l|c|c|c|}
\hline \multicolumn{1}{|c|}{ Photocatalyst } & $\begin{array}{c}\text { Wavelength } \\
(\mathrm{nm})\end{array}$ & $\begin{array}{c}\text { Specific Surface } \\
\text { Area } \\
\left(\mathrm{m}^{2} / \mathrm{g}\right)\end{array}$ & $\begin{array}{c}\text { Particle } \\
\text { Length } \\
(\boldsymbol{\mu})\end{array}$ \\
\hline Zinc oxide $(\mathrm{ZnO})$ & 388 & 3.37 & $2.2 \pm 0.4$ \\
\hline Hematite $\left(\alpha-\mathrm{Fe}_{2} \mathrm{O}_{3}\right)$ & 590 & 26.32 & $0.3 \pm 0.1$ \\
\hline Copper oxide $(\mathrm{CuO})$ & 729 & 5.94 & $1.5 \pm 0.2$ \\
\hline Titanium dioxide, $\mathrm{P} 25\left(\mathrm{TiO}_{2}\right)$ & 376 & 53.66 & $6.1 \pm 0.1$ \\
\hline
\end{tabular}

Asenath-Smith et al. (2019) rigorously characterized the illumination system. The tungsten-halogen illumination system provided broad-spectrum irradiation that included the wavelengths corresponding to the bandgaps of all three target solutions. As shown in Figure 2, the greatest irradiance is present at the relevant wavelength for $\mathrm{CuO}$, and very little irradiance is present at the relevant wavelengths for $\mathrm{ZnO}$ and $\mathrm{TiO}_{2}$. Tungsten-halogen illumination was selected both for its output of irradiance at the relevant wavelengths for all three photocatalysts and, as a black body illuminator,

* E. Asenath-Smith, E. K. Ambrogi, E. Barnes, and J. A. Brame, “Colloidal $\mathrm{Fe}_{2} \mathrm{O}_{3}$ with enhanced photocatalytic activity achieved by reactive oxygen species pairing with CuO" (unpublished manuscript, U.S. Army Engineer Research and Development Center, Hanover, NH, 2020), Microsoft Word file. 
its similarity in distribution to solar irradiance (Figure 2). Therefore, tungsten-halogen illumination was an ideal light source to study our materials' suitability for both artificially lit systems and solar-light harvesting.

Figure 2. Spectral irradiance of a tungsten-halogen illumination system and outdoor solar irradiance.

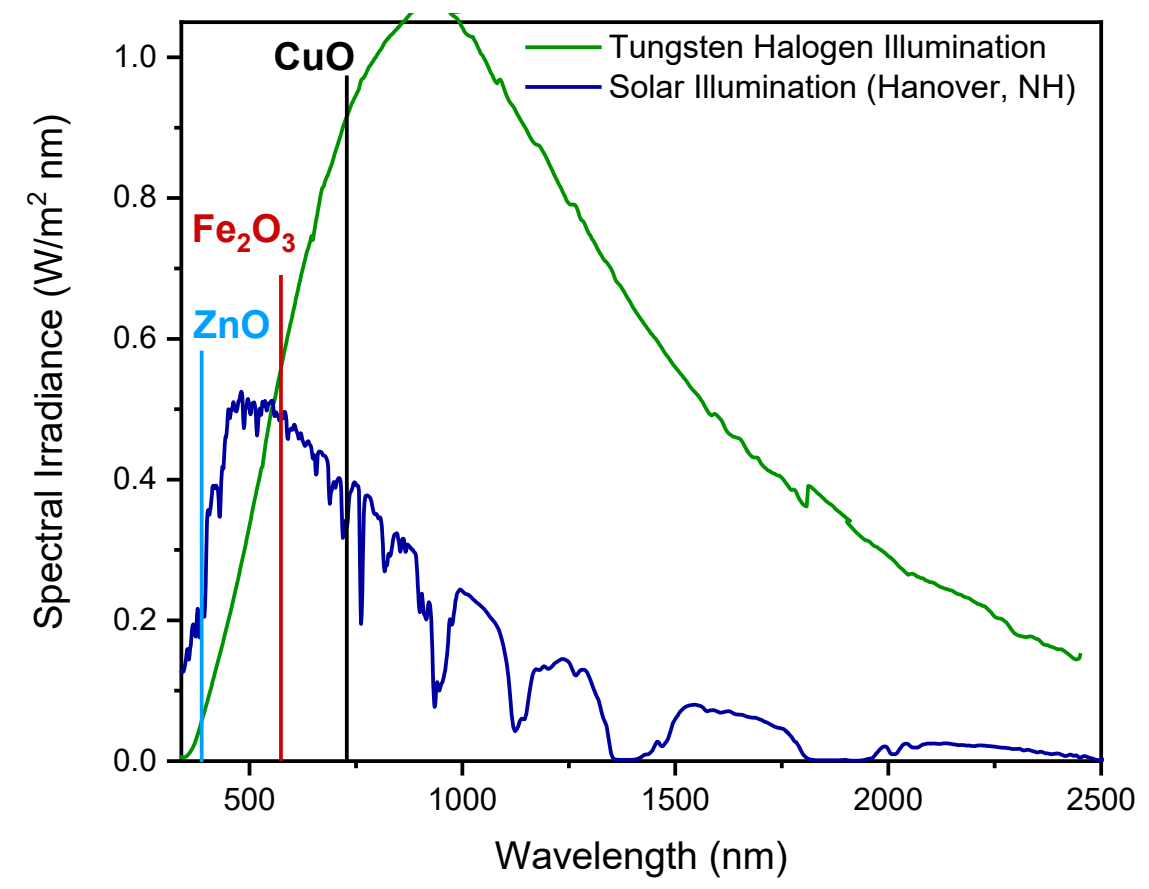

\subsection{Degradation of methyl orange by individual photocatalysts and multispectral materials}

We evaluated the performance of each individual photocatalyst by first studying the degradation of MO. Each photocatalytic experiment had $100 \mu \mathrm{L}$ of $30 \%$ hydrogen peroxide solution added to it at illumination time zero. Each photocatalytic experiment followed pseudo-first-order degradation kinetics, meaning that the natural $\log$ of concentration values versus time was linear in nature, where the rate constant $k$ is the slope of this line. Figure 3 shows the pseudo-first-order kinetics for the individual photocatalysts, where $\alpha-\mathrm{Fe}_{2} \mathrm{O}_{3}$ showed the fastest degradation, followed by $\mathrm{CuO}$, $\mathrm{P} 25$, and $\mathrm{ZnO}$. The low $\mathrm{MO}$ degradation rates for $\mathrm{ZnO}$ and P25 $(k=1.6 \pm$ 0.1 E-03 and $2.3 \pm 0.1 \mathrm{E}-03$, respectively) correspond to relatively low irradiance of the tungsten-halogen illumination system at UVA wavelengths, which correspond to the bandgaps of these materials. The $\alpha-\mathrm{Fe}_{2} \mathrm{O}_{3}$ outperformed $\mathrm{CuO}$ despite more light intensity being present at the relevant wavelengths for $\mathrm{CuO}$. However, the $\mathrm{\alpha}-\mathrm{Fe}_{2} \mathrm{O}_{3}$ particles have approximately 5 times greater surface area than the $\mathrm{CuO}$ particles. 
Figure 3. Degradation of methyl orange with individual and multispectral photocatalysts under tungsten-halogen illumination.

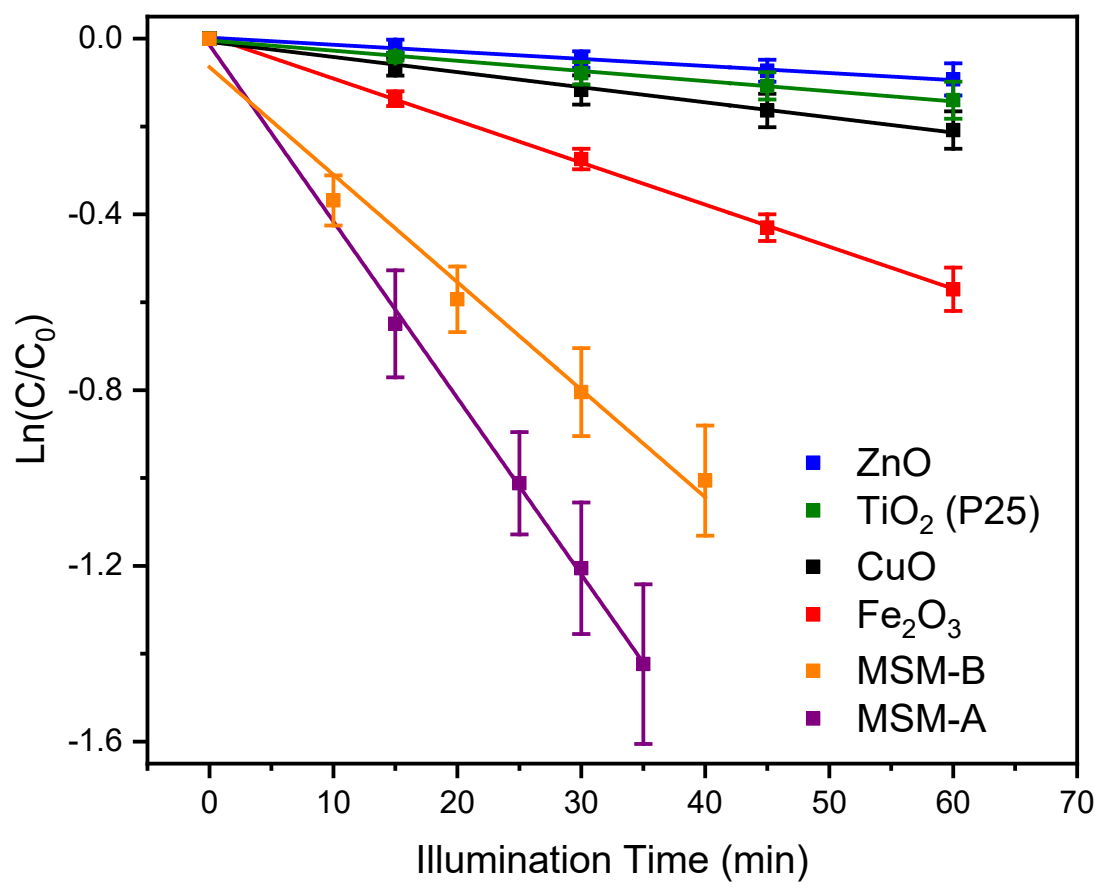

This study also evaluated two mixtures of photocatalysts with the degradation of MO under tungsten-halogen illumination. MSM-A contained $15 \mathrm{mg}$ $\alpha-\mathrm{Fe}_{2} \mathrm{O}_{3}$ and $7.5 \mathrm{mg} \mathrm{CuO}$, a 2:1 mass ratio of $\alpha-\mathrm{Fe}_{2} \mathrm{O}_{3}$ to $\mathrm{CuO}$. MSM-B contained 7.5 $\mathrm{mg} \mathrm{ZnO}, 15 \mathrm{mg} \alpha-\mathrm{Fe}_{2} \mathrm{O}_{3}$, and $7.5 \mathrm{mg} \mathrm{CuO}$, a 1:2:1 ratio of $\mathrm{ZnO}$ to $\alpha-\mathrm{Fe}_{2} \mathrm{O}_{3}$ to $\mathrm{CuO}$. The rate constant of MSM-A was twice that of MSM-B despite less photocatalytic material being present in the same amount of solution. In addition, the rate constants for both multispectral materials were greater than the sum of the rate constants for their individual photocatalyst components. This apparent synergy between photocatalytic materials, and especially between $\alpha-\mathrm{Fe}_{2} \mathrm{O}_{3}$ and $\mathrm{CuO}$, was found to be a result of the common hydroxyl radical reactive oxygen species that $\alpha-\mathrm{Fe}_{2} \mathrm{O}_{3}$ and $\mathrm{CuO}$ share. Table 2 shows the rate constants, $k$, for the reactions with individual and multispectral photocatalysts. Because MSM-A showed the greatest degradation rate for $\mathrm{MO}$, we chose it as the material composition to test with a more complicated, multicontaminant system that might be encountered in real wastewater treatment scenarios. 
Table 2. Pseudo-first-order rate constants for degradation of methyl orange with individual photocatalysts and multispectral materials.

\begin{tabular}{|c|c|}
\hline Photocatalyst & Rate Constant $k\left(\mathrm{~min}^{-1}\right)$ \\
\hline $\mathrm{TiO}_{2}$ & $2.3 \pm 0.1 \mathrm{E}-03$ \\
\hline $\mathrm{ZnO}$ & $1.6 \pm 0.1 \mathrm{E}-03$ \\
\hline$\alpha-\mathrm{Fe}_{2} \mathrm{O}_{3}$ & $9.6 \pm 0.1 \mathrm{E}-03$ \\
\hline $\mathrm{CuO}$ & $3.4 \pm 0.2 \mathrm{E}-03$ \\
\hline $\mathrm{MSM}-\mathrm{A}$ & $40 \pm 1 \mathrm{E}-03$ \\
\hline $\mathrm{MSM}-\mathrm{B}$ & $20 \pm 1 \mathrm{E}-03$ \\
\hline
\end{tabular}

\subsection{Degradation of multicontaminant mixtures by multispectral materials under laboratory illumination}

MSM-A was used to degrade a mixture of three contaminants: MO, used in test studies described above; $\mathrm{CM}$, a pharmaceutical and well known recalcitrant contaminant (Benotti et al. 2009; Malchi et al. 2014); and NB, an industrial chemical and contaminant of emerging concern (Richardson and Ternes 2011). The concentrations of MO, CM, and NB in the mixture were 25, 25, and $50 \mu \mathrm{M}$, respectively. Ambrogi et al. (2019) previously evaluated these same contaminants in a wide range of advanced oxidation processes.

Figure 4a shows the pseudo-first-order degradation kinetics of the contaminant mixture, and Table 3 lists the rate constants. When MSM-A was used to degrade this multicontaminant mixture, the degradation rate for MO was slightly lower than when MSM-A was used to degrade MO alone ( $0.030 \pm 0.001 \mathrm{~min}^{-1}$ versus $0.040 \pm 0.001 \mathrm{~min}^{-1}$, respectively). The degradation rate for $\mathrm{CM}$ in the multicontaminant system was $0.024 \pm 0.001$ $\mathrm{min}^{-1}$, close to the degradation rate of MO. Interestingly, the degradation rate for NB was 4-5 times lower, $0.006 \pm 0.001 \mathrm{~min}^{-1}$. This slower degradation rate for NB is consistent with results for NB degraded in contaminant mixtures with other advanced oxidation processes. For example, when the same contaminant mixture was degraded with commercial $\mathrm{TiO}_{2}$, MO had a degradation rate of $0.023 \mathrm{~min}^{-1}$ while NB had a $k$ of 0.0068 $\min ^{-1}$ (Ambrogi et al. 2019). Although NB initially degraded slowly in the contaminant mixture, the concentration profile (Figure $4 \mathrm{~b}$ ) for extended experiment times (1-2 hr) shows that NB disappears more quickly after 30 min, when more than $50 \%$ of the $\mathrm{CM}$ and $\mathrm{MO}$ have been degraded. 
Figure 4. Degradation of the three-contaminant mixture with multispectral material under tungsten-halogen illumination.

(a)

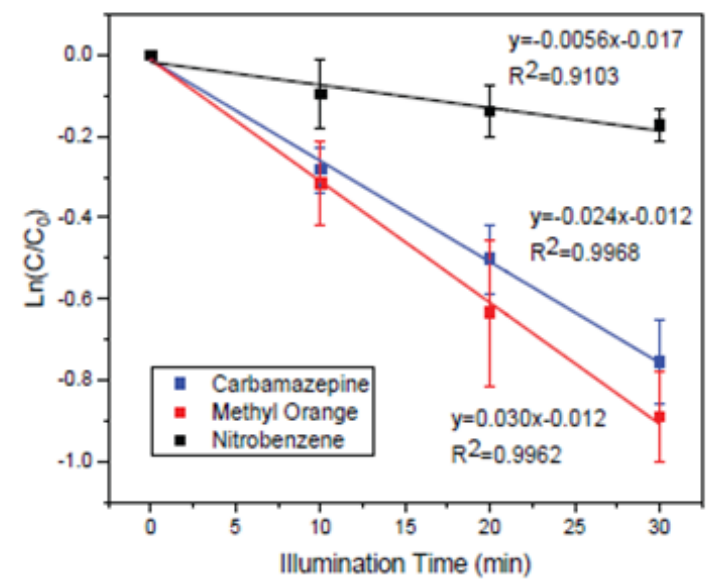

(b)

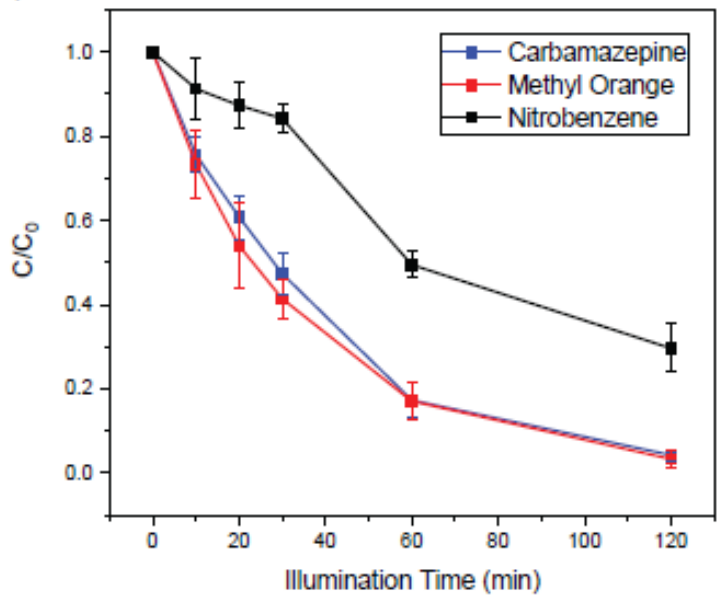

Table 3. Pseudo-first-order rate constants for contaminants degraded with MSM-A.

\begin{tabular}{|l|c|}
\hline \multicolumn{1}{|c|}{ Contaminant } & Rate Constant $k\left(\mathrm{~min}^{-1}\right)$ \\
\hline Methyl Orange (MO) & $0.030 \pm 0.001$ \\
\hline Carbamazepine (CM) & $0.024 \pm 0.001$ \\
\hline Nitrobenzene (NB) & $0.006 \pm 0.001$ \\
\hline
\end{tabular}

\subsection{Observed degradation products of contaminants}

We studied the degradation of the contaminant mixture by HPLC-MS to identify degradation byproducts of the contaminants. The chromatograms revealed three unique degradation products of MO (Figure 5). These structures were identified based on mass spectra (see Appendix A) and information from Chen et al. (2008). Samples of MO degraded with each of the individual photocatalysts were analyzed after $30 \mathrm{~min}$. Respective chromatograms for $\mathrm{MO}$ photodegradation by $\mathrm{ZnO}, \alpha-\mathrm{Fe}_{2} \mathrm{O}_{3}$, and $\mathrm{CuO}$ are shown in Figure 6a, b, and c. Figure 6a, b, and c shows 15\%, 65\%, and 25\% degradation of MO after $30 \mathrm{~min}$, respectively. Despite the different amounts of degradation, all three reactions show only product $\mathrm{B}$.

Figure 7 shows the MO degradation by MSM-A and MSM-B analyzed with HPLC-MS. Figure 7a shows the degradation with MSM-A after 10 min, which corresponds to $65 \%$ methyl orange degradation. Figure $7 \mathrm{~b}$ shows the degradation with MSM-B after $30 \mathrm{~min}$, which corresponds to $55 \% \mathrm{MO}$ degradation. Notably, products $\mathrm{A}, \mathrm{B}$, and $\mathrm{C}$ are all detected in the spectra depicting $\mathrm{MO}$ degradation with $\mathrm{MSM}-\mathrm{A}$ (the $\mathrm{CuO}-\mathrm{Fe}_{2} \mathrm{O}_{3}$ mixture); but only 
product $\mathrm{B}$ is observed when MO is degraded with MSM-B. This indicates the unique mechanism of photocatalyst synergy present in MSM-A that results in the enhanced degradation rate. It is notable that both products $\mathrm{A}$ and $\mathrm{B}$ correspond to the addition of hydroxyl radicals to $\mathrm{MO}$, while product $\mathrm{B}$ is the result of the removal of a methyl group. Products A and $\mathrm{C}$ being observed as a result of the synergistic material indicates that the degradation mechanism is driven primarily by hydroxyl radicals, a result confirmed by other investigations. ${ }^{*}$

We also used HPLC-MS to detect the byproducts observed during degradation of the contaminant mixture and to confirm complete removal of the contaminants by the multispectral material. Figure 8 shows the contaminants and byproducts labeled on the chromatograms. CM, MO, and their byproducts were degraded from the solution by 180 min of reaction time. At 240 minutes of reaction time, more than $90 \%$ of the NB was removed from the solution.

Figure 5. Observed degradation products of methyl orange.

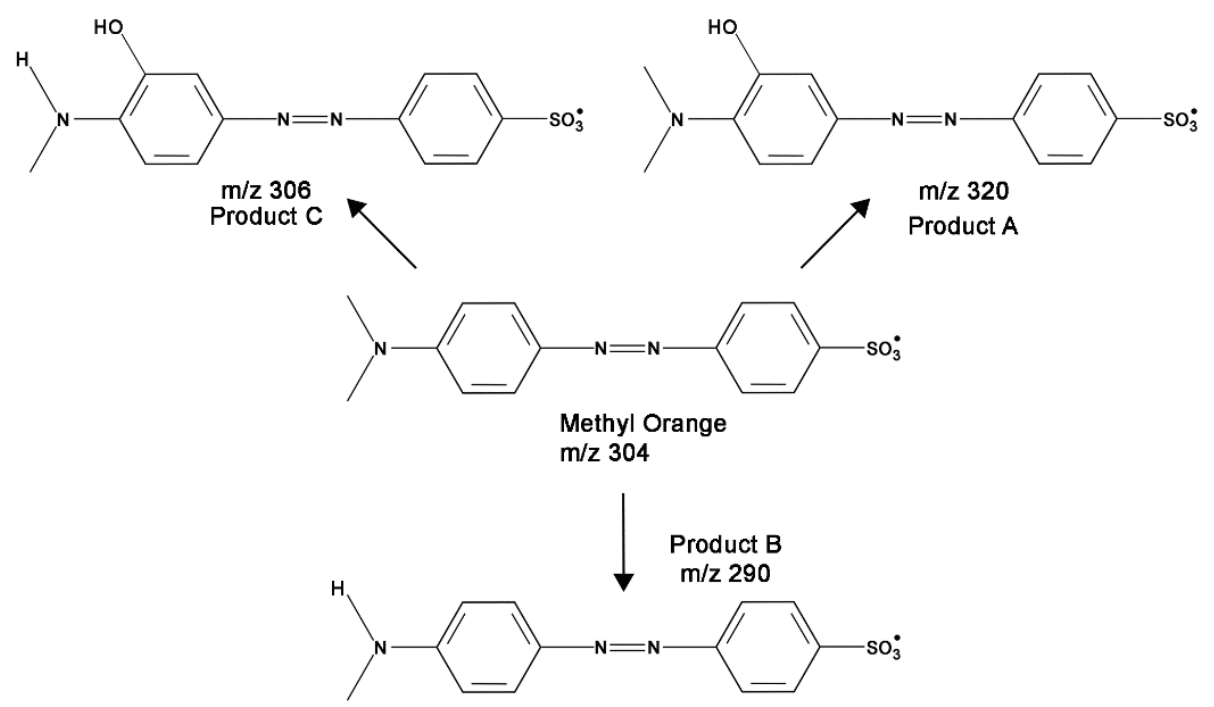

* E. Asenath-Smith, E. K. Ambrogi, E. Barnes, and J. A. Brame, “Colloidal $\mathrm{Fe}_{2} \mathrm{O}_{3}$ with Enhanced Photocatalytic Activity Achieved by Reactive Oxygen Species Pairing with CuO” (unpublished manuscript, U.S. Army Engineer Research and Development Center, Hanover, NH, 2020), Microsoft Word file. 
Figure 6. Methyl orange degradation products observed with (a) $\mathrm{ZnO}$, (b) $\alpha-\mathrm{Fe}_{2} \mathrm{O}_{3}$, and (c) $\mathrm{CuO}$.

(a)

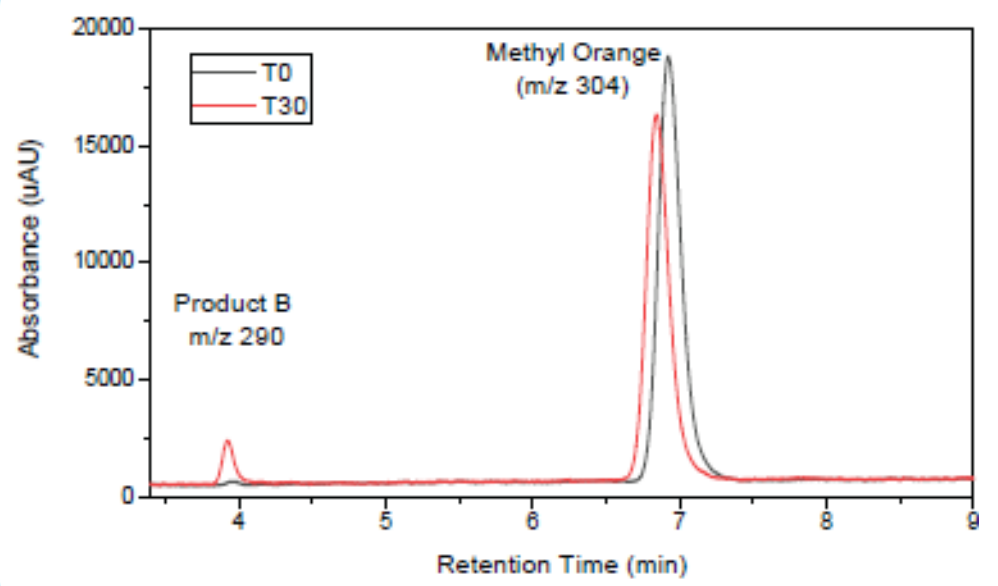

(b)

(c)
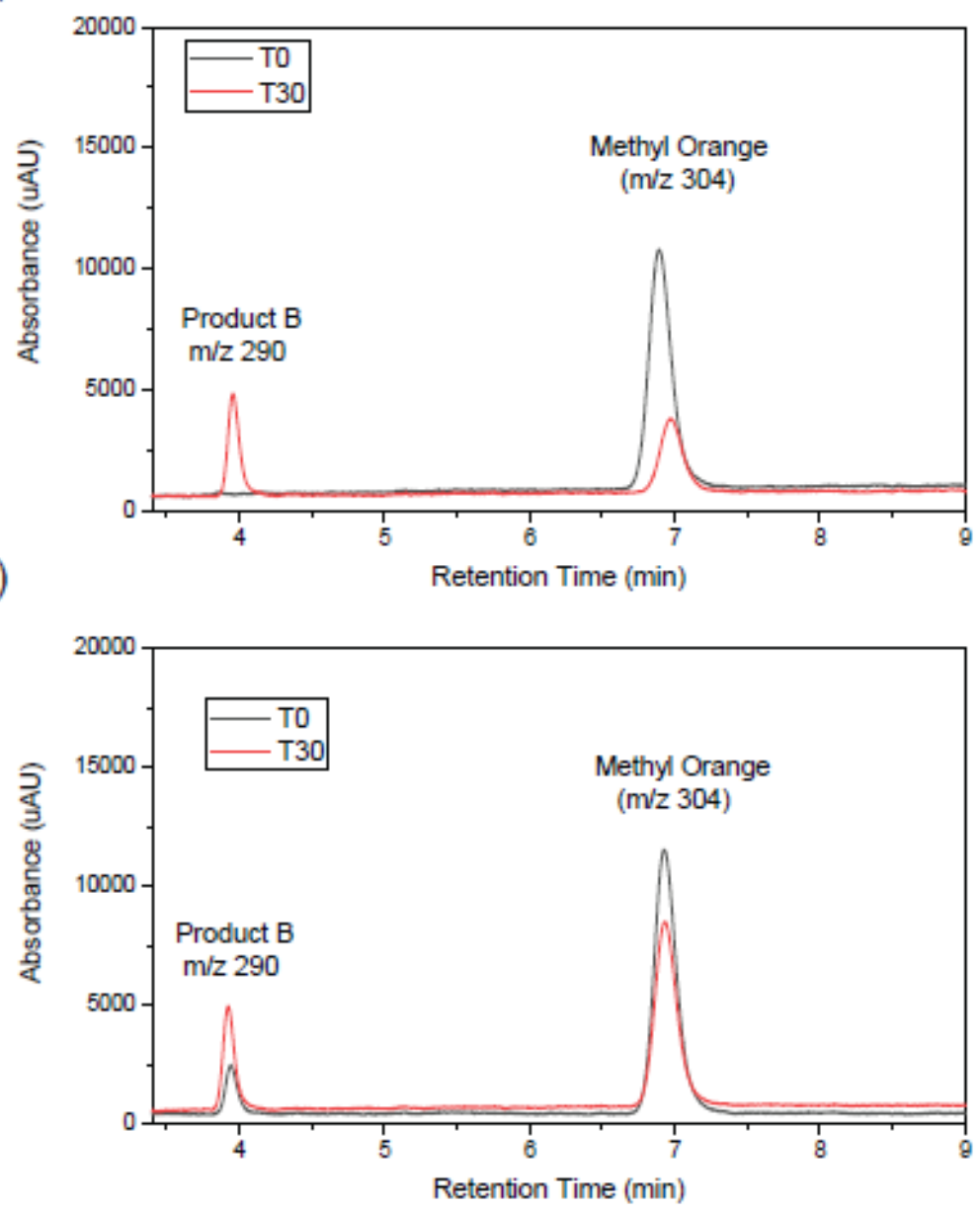
Figure 7. Methyl orange degradation products observed with (a) MSM-A and (b) MSM-B.

(a)

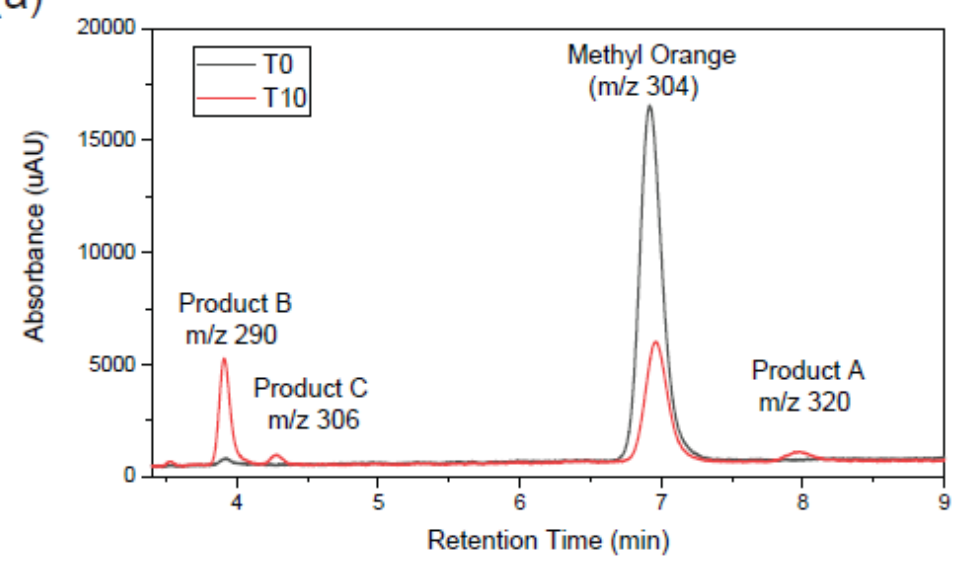

(b)

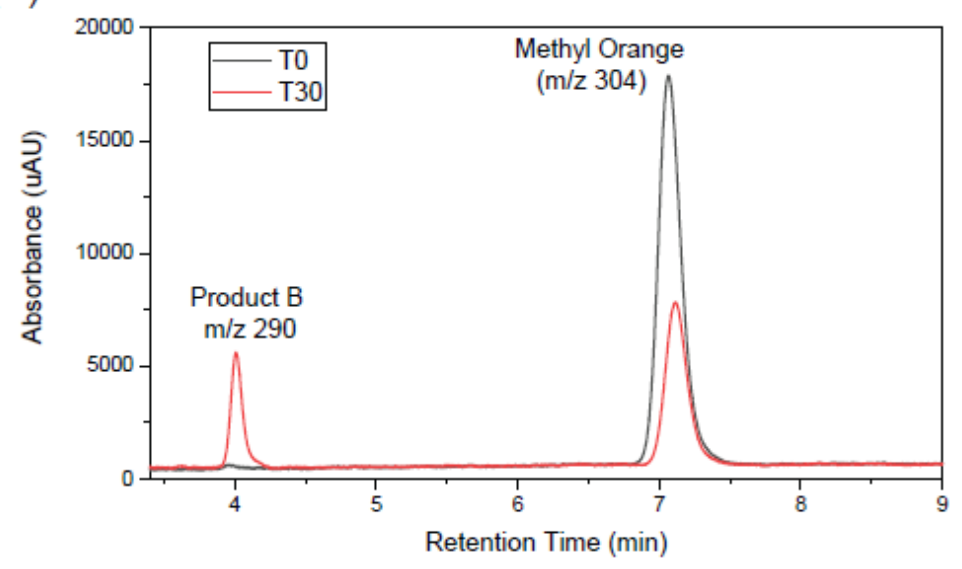

Figure 8. HPLC-MS chromatograph of multicontaminant degradation with multispectral material.

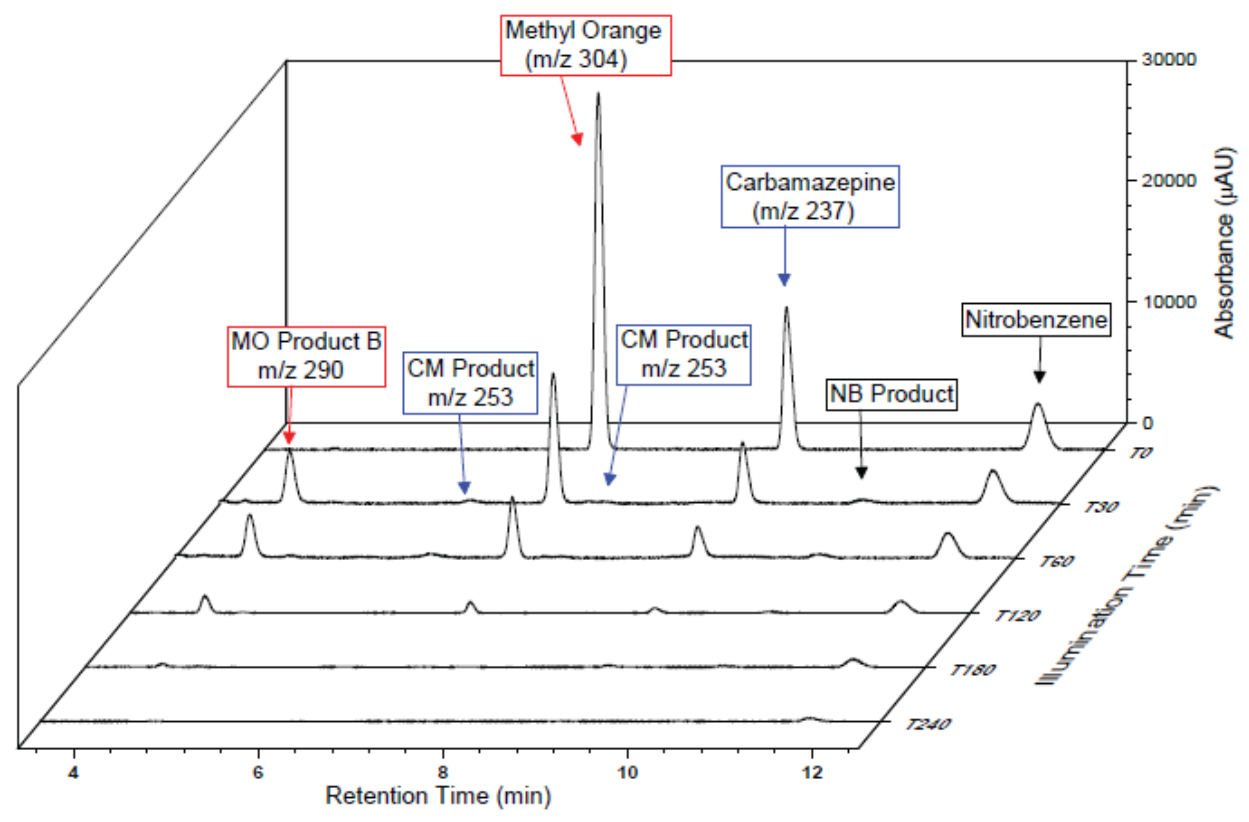


Table 4 lists the peaks observed in the degradation of the multicontaminant mixture. Interestingly, when the contaminant mixture was degraded with MSM-A, we observed only one MO product, product B. However, we observed two CM products, both of which correspond to a hydroxyl radical addition to CM. Because of the limitations of the HPLC-MS detector, it is not possible to distinguish the exact structures of the byproducts; however, there are three possible sites for a hydroxyl radical addition on the CM molecule (Jelic et al. 2013) (Table 4). The NB byproducts were also not able to be identified, but phenol is a possible product suggested by Li et al. (2006).

Table 4. Chromatographic peaks observed in the degradation of the three-contaminant mixture.

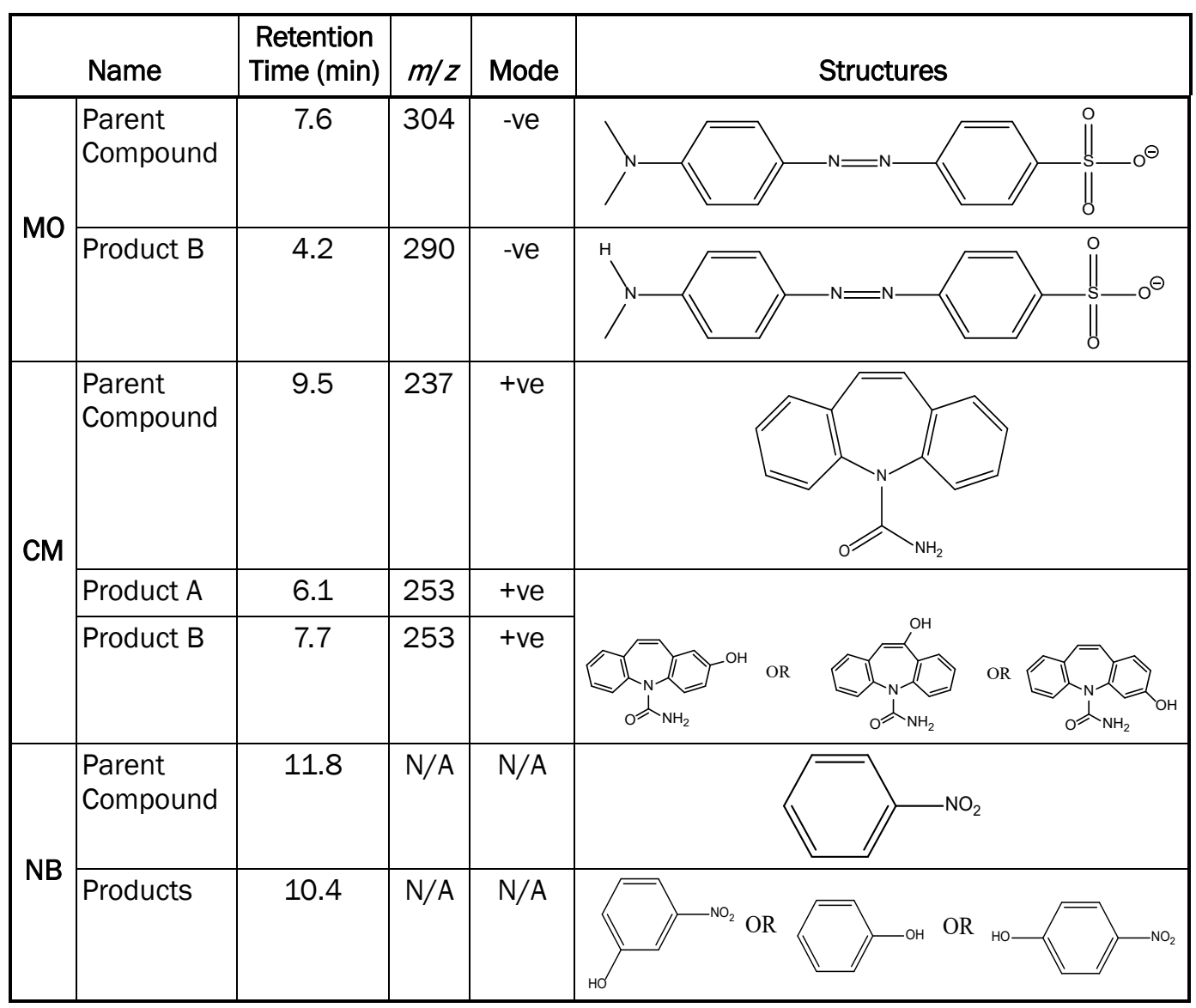

\subsection{Multispectral material as a solar-light-driven photocatalyst}

Given the effectiveness of our multispectral materials in a laboratory system, we tested them outside under solar illumination to verify our hypothesis that these materials would be suitable for photodegradation reactions under solar illumination. We identified 21 June, the summer solstice, as an ideal time for outdoor testing and carried out the testing in a flat open area 
outside in Hanover, New Hampshire. Figure 9 shows the solar irradiance at noon on the day of the testing as measured with a calibrated spectroradiometer. We tested MSM-A and $\mathrm{TiO} 2$ with the contaminant mixture, as well as a blank contaminant mixture solution, under outdoor illumination to measure the photolysis rates of the contaminants. Figure 10 shows the first-order rate constants measured in these experiments. The rate constants for MSM-A were approximately two times greater than those observed under laboratory illumination, despite similar or less available irradiance at the wavelengths for $\alpha-\mathrm{Fe}_{2} \mathrm{O}_{3}$ and $\mathrm{CuO}$ (see Figure 9 and Figure 2). The rate constants observed with $\mathrm{TiO}_{2}$ were approximately 10 times greater than under tungsten-halogen illumination, corresponding to the increase in radiance at UVA wavelengths. However, the rate constants for the multispectral material were more than two times the rate constants for commercial $\mathrm{TiO}_{2}$, indicating the unique suitability of our material for lowenergy input, solar-light-driven applications.

Figure 9. Solar spectral irradiance in Hanover, New Hampshire, on 21 June 2018.

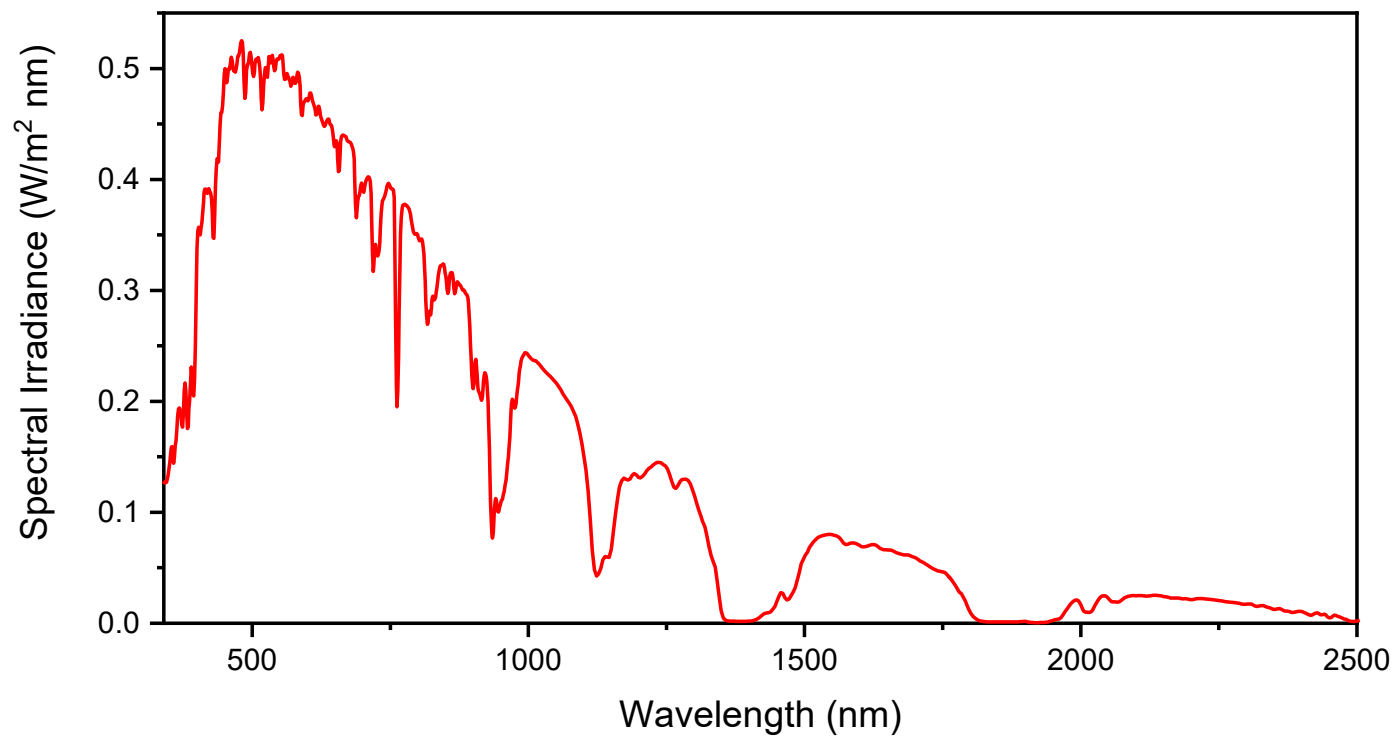


Figure 10. Rate constants for degradation of contaminants in outdoor experiments with multispectral photocatalyst and controls.

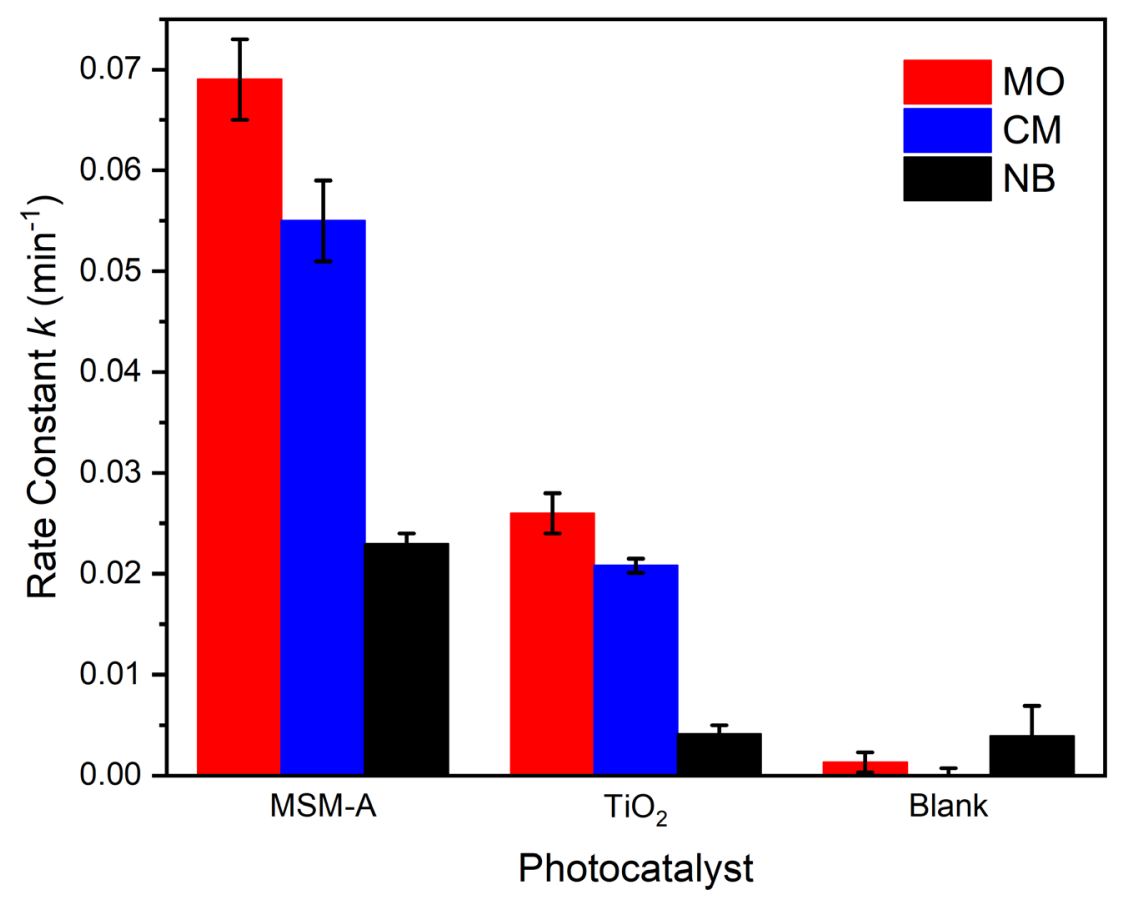

\subsection{Electrical Energy per Order of multispectral photocatalysts}

To evaluate the effectiveness of the multispectral photocatalysis as an advanced oxidation process for water treatment, we calculated a figure of merit known as Electrical Energy per Order $\left(E_{E O}\right)$. This metric can be compared against other advanced oxidation processes to evaluate their efficiency of contaminant removal. A lower $E_{E O}$ value corresponds to a more efficient advanced oxidation process. The calculations for $E_{E O}$, as well as Collector Area per Order $\left(A_{C O}\right)$, the equivalent metric for solar-driven processes, are explained in detail below.

\subsubsection{Calculating Electrical Energy per Order and Collector Area per Order}

First described by Bolton et al. (2001), $E_{E O}$ is a figure of merit for advanced oxidation processes. The $E_{E O}$ value for a particular advanced oxidation reactor describes the electrical energy needed to remove a particular contaminant from the system by an order of magnitude value. For processes with a first-order rate constant, EEO can be calculated using equation (1):

$$
E_{E O}=\frac{38.4 * P}{V * k},
$$


where

$$
\begin{aligned}
P= & \text { the power input to the system in kilowatts, } \\
V= & \text { the volume in liters, and } \\
k= & \text { the pseudo-first-order rate constant in inverse hours for the } \\
& \quad \text { contaminant removal. }
\end{aligned}
$$

Bolton et al. (2001) also described an equivalent figure of merit for advanced oxidation processes driven by sunlight. $A_{C O}$ represents the amount of surface area that must be exposed to sunlight to reduce the concentration of a contaminant by an order of magnitude. For processes with a firstorder rate constant, Aco can be calculated using equation (2):

$$
A_{C O}=\frac{A * E_{S} * 0.384}{V * k}
$$

where

$$
\begin{aligned}
A= & \text { the illuminated area of the solution in square meters; } \\
E_{s}= & \text { the spectral irradiance, in watts per square meters, integrated } \\
& \text { over all measured values; } \\
V= & \text { the volume in liters; and } \\
k= & \text { the pseudo-first-order rate constant in inverse hours for the } \\
& \text { contaminant removal. }
\end{aligned}
$$

\subsection{2 $E_{E O}$ of individual and multispectral photocatalysts under tungsten- halogen illumination}

We calculated $E_{E O}$ values for the individual and multispectral photocatalysts used to degrade MO. The calculations used the pseudo-first-order rate constants, which had been converted to inverse hours (Table 5), and the power usage of the laboratory tungsten-halogen illumination system, approximately $0.1 \mathrm{~kW}$. Because all photocatalysts were run with the same illumination system, the relative rank of the $E_{E O}$ values is the same as the rate constants, with the lowest $E_{E O}$ value (40 kWh/order*m3) corresponding to the material with the greatest MO degradation rate, MSM-A. The $E_{E O}$ calculations show that not only do the multispectral materials outperform commercial $\mathrm{TiO}_{2}$ under tungsten-halogen illumination, but they are also comparable to $\mathrm{TiO}_{2}$ in a fluorescent UVA illumination system that outputs only wavelengths corresponding to the $\mathrm{TiO}_{2}$ bandgap. Previous reports found $\mathrm{TiO}_{2}$ to have an $E_{E O}$ of $39 \mathrm{kWh} /$ order*m$^{*}$ when used to degrade MO under 
similar illumination conditions (Ambrogi et al. 2019). Table 5 shows all $E_{E O}$ values for the individual and multispectral photocatalysts.

Table 5. EEO values for the degradation of methyl orange under tungsten-halogen illumination with individual and multispectral photocatalysts.

\begin{tabular}{|l|c|c|}
\hline \multicolumn{1}{|c|}{ Photocatalyst } & $\begin{array}{c}\text { Rate Constant } \\
\left(\mathrm{h}^{-1}\right)\end{array}$ & $\begin{array}{c}E_{E O} \\
\left(\mathrm{kWh} / \text { order*m}^{3}\right)\end{array}$ \\
\hline $\mathrm{TiO}_{2}(\mathrm{P} 25)$ & 0.14 & 696 \\
\hline $\mathrm{ZnO}$ & 0.10 & 1000 \\
\hline$\alpha-\mathrm{Fe}_{2} \mathrm{O}_{3}$ & 0.58 & 167 \\
\hline $\mathrm{CuO}$ & 0.20 & 470 \\
\hline $\mathrm{MSM}-\mathrm{A}$ & 2.40 & 40 \\
\hline $\mathrm{MSM}-\mathrm{B}$ & 1.20 & 80 \\
\hline
\end{tabular}

\subsection{3 $E_{E O}$ and $A_{C O}$ of multispectral, multicontaminant systems}

We calculated $E_{E O}$ values for the contaminant mixture degraded with MSM-A. Shown in Table 6, MO degradation had the lowest value, followed by $\mathrm{CM}$ and then by NB. As with the values in section 3.6.2, the lowest $E_{E O}$ value corresponds to the greatest degradation rate constant. These $E_{E O}$ values show that MSM-A is also on par with commercial $\mathrm{TiO}_{2}$ (under UVA illumination) when used to degrade a contaminant mixture. Ambrogi et al. (2019) found that MO, CM, and NB had EEO values of 34, 104, and 115 $\mathrm{kWh} /$ order*m3 , respectively, with $\mathrm{TiO}_{2}$ under such conditions.

Table 6. $E_{E O}$ and $A_{C O}$ values for the degradation of the multicontaminant mixture with MSM-A under laboratory and solar illumination.

\begin{tabular}{|l|l|c|c|c|}
\hline \multirow{3}{*}{ Experiment } & \multirow{2}{*}{ Photocatalyst } & \multicolumn{3}{|c|}{$E_{\text {EO or }}$ AcO $(\mathrm{kWh} /$ order/m } \\
\cline { 3 - 5 } & MO & $\mathrm{CM}$ & $\mathrm{NB}$ \\
\hline \multirow{3}{*}{ Indoor } & $\mathrm{MSM}-\mathrm{A}$ & 53 & 67 & 285 \\
\hline \multirow{3}{*}{ Outdoor } & $\mathrm{MSM}-\mathrm{A}$ & 4.0 & 6.1 & 14.5 \\
\cline { 2 - 5 } & $\mathrm{TiO}_{2}$ & 12.9 & 16.1 & 81.5 \\
\cline { 2 - 5 } & Blank & 334 & $\mathrm{~N} / \mathrm{A}$ & 85.7 \\
\hline
\end{tabular}

We also calculated $A c o$ values for the experiments conducted outside with MSM-A and controls (Table 6). Because of the increased rate constants under solar illumination, MSM-A greatly outperformed $\mathrm{TiO}_{2}$ and UV photolysis for all contaminants. For MO and CM, the values were less than 10 $\mathrm{kWh} /$ order $^{*} \mathrm{~m}^{3}$, which is a standard of feasibility for advanced oxidation processes used in commercial applications (Santiago-Morales et al. 2013; 
Sindelar et al. 2014; Yao et al. 2018). Thus, the multispectral photocatalytic materials are certainly suitable candidates for solar-light-harvesting water treatment applications. 


\section{Conclusions}

By combining transition metal oxide photocatalysts with different bandgap energies, we were able to achieve increased photodegradation kinetics for removal of small molecule contaminants from aqueous solutions. The increased degradation rates measured for the optimized TMO photocatalytic material exceed the sum of the photodegradation rates for the individual oxides alone, implying a synergy that is related to more than just increased light harvesting by multiple oxides. These multispectral materials have efficiencies on par with commercially available photocatalysts, and they show promising performance in outdoor reactions. These findings provide a straightforward methodology to leverage broad-spectrum solar radiation as an energy-efficient means to remediate small molecule contaminants from water as a final purifying step in a wastewater treatment train. 


\section{References}

Ahmed, S., M. G. Rasul, R. Brown, and M. A. Hashib. 2011. "Influence of Parameters on the Heterogeneous Photocatalytic Degradation of Pesticides and Phenolic Contaminants in Wastewater: A Short Review.” Journal of Environmental Management 92 (3): 311-330.

Ambrogi, E. K., E. Asenath-Smith, W. A. Ballard, L. C. Moores, and J. A. Brame. 2019. Cross-Comparison of Advanced Oxidation Processes for Remediation of Organic Pollutants in Water Treatment Systems. ERDC TR-19-3. Hanover, NH: U.S. Army Engineer Research and Development Center.

Andreozzi, R., M. Raffaele, and P. Nicklas. 2003. "Pharmaceuticals in STP Effluents and Their Solar Photodegradation in Aquatic Environment." Chemosphere 50 (10): 1319-1330.

Asenath-Smith, E., E. K. Ambrogi, L. C. Moores, S. D. Newman, and J. A. Brame. 2019. "Leveraging Chemical Actinometry and Optical Radiometry to Reduce Uncertainty in Photochemical Research.” Journal of Photochemistry and Photobiology A: Chemistry 372: 279-287.

Asenath-Smith, E., R. Hovden, L. F. Kourkoutis, and L. A. Estroff. 2015. "Hierarchically Structured Hematite Architectures Achieved by Growth in a Silica Hydrogel." Journal of the American Chemical Society 137 (15): 5184-5192.

Asenath-Smith, E., J. M. Noble, R. Hovden, A. M. Uhl, A. DiCorato, Y.-Y. Kim, A. N. Kulak, F. C. Meldrum, L. F. Kourkoutis, and L. A. Estroff. 2016. "Physical Confinement Promoting Formation of $\mathrm{Cu}_{2} \mathrm{O}-\mathrm{Au}$ Heterostructures with $\mathrm{Au}$ Nanoparticles Entrapped within Crystalline Cu2O Nanorods." Chemistry of Materials 29 (2): 555-563.

Benotti, M. J., R. A. Trenholm, B. J. Vanderford, J. C. Holady, B. D. Stanford, and S. A. Snyder. 2009. "Pharmaceuticals and Endocrine Disrupting Compounds in U.S. Drinking Water.” Environmental Science and Technology 43 (3): 597-603.

Bloh, J. Z., R. Dillert, and D. W. Bahnemann. 2012. “Designing Optimal Metal-Doped Photocatalysts: Correlation between Photocatalytic Activity, Doping Ratio, and Particle Size.” The Journal of Physical Chemistry C 116 (48): 25558-25562.

Bolton, J. R., K. G. Bircher, W. Tumas, and C. A. Tolman. 2001. "Figures-of-Merit for the Technical Development and Application of Advanced Oxidation Technologies for Both Electric- and Solar-Driven Systems." Pure and Applied Chemistry 73 (4): 627-637. https://doi.org/10.1351/pac200173040627.

Bora, L. V., and R. K. Mewada. 2017. "Visible/Solar Light Active Photocatalysts for Organic Effluent Treatment: Fundamentals, Mechanisms and Parametric Review." Renewable and Sustainable Energy Reviews 76:1393-1421. https://doi.org/10.1016/i.rser.2017.01.130.

Cha, H. G., S. J. Kim, K. J. Lee, M. H. Jung, and Y. S. Kang. 2011. "Single-Crystalline Porous Hematite Nanorods: Photocatalytic and Magnetic Properties.” The Journal of Physical Chemistry C 115 (39): 19129-19135. 
Chen, T., Y. Zheng, J. M. Lin, and G. Chen. 2008. "Study on the Photocatalytic Degradation of Methyl Orange in Water Using Ag/ZnO as Catalyst by Liquid Chromatography Electrospray Ionization Ion-Trap Mass Spectrometry.” Journal of the American Society Mass Spectrometry 19 (7): 997-1003.

Chen, X., D. Chu, L. Wang, W. Hu, H. Yang, J. Sun, S. Zhu, G. Wang, J. Tao, and S. Zhang. 2018. "Surfactant-Free Synthesis of Novel Hierarchical Dahlia-Like $\mathrm{SnO}_{2}$ Nanostructures with Enhanced Visible-Light-Driven Photocatalytic Activity.” Journal of Alloys and Compounds 768: 517-524.

Choi, Y., M. S. Koo, A. D. Bokare, D. H. Kim, D. W. Bahnemann, and W. Choi. 2017. "Sequential Process Combination of Photocatalytic Oxidation and Dark Reduction for the Removal of Organic Pollutants and $\mathrm{Cr}(\mathrm{VI})$ using $\mathrm{Ag} / \mathrm{TiO}_{2}$." Environmental Science and Technology 51 (7): 3973-3981.

de Lasa, H., B. Serrano, and M. Salaices. 2005. Photocatalytic Reaction Engineering. New York: Springer Science and Business Media.

Frandsen, C., B. A. Legg, L. R. Comolli, H. Zhang, B. Gilbert, E. Johnson, and J. F. Banfield. 2014. "Aggregation-Induced Growth and Transformation of $\beta-\mathrm{FeOOH}$ Nanorods to Micron-Sized $\alpha-\mathrm{Fe}_{2} \mathrm{O}_{3}$ spindles.” CrystEngComm 16 (8): 1451-1458.

Ghosh Chaudhuri, R., and S. Paria. 2012. "Core/Shell Nanoparticles: Classes, Properties, Synthesis Mechanisms, Characterization, and Applications." Chemical Reviews 112 (4): 2373-2433. https://doi.org/10.1021/cr100449n.

Glassmeyer, S. T., E. T. Furlong, D. W. Kolpin, A. L. Batt, R. Benson, J. S. Boone, O. Conerly, M. J. Donohue, D. N. King, M. S. Kostich, H. E. Mash, S. L. Pfaller, K. M. Schenck, J. E. Simmons, E. A. Varughese, S. J. Vesper, E. N. Villegas, and V. S. Wilson. 2017. "Nationwide Reconnaissance of Contaminants of Emerging Concern in Source and Treated Drinking Waters of the United States." Science of the Total Environment 581-582:909-922.

Gorito, A. M., A. R. Ribeiro, C. R. Gomes, C. M. R. Almeida, and A. M. T. Silva. 2018. "Constructed Wetland Microcosms for the Removal of Organic Micropollutants from Freshwater Aquaculture Effluents." Science of the Total Environment 644:1171-1180.

Gupta, V. K., I. Ali, T. A. Saleh, A. Nayak, and S. Agarwal. 2012. "Chemical Treatment Technologies for Waste-Water Recycling-An Overview.” RSC Advances 2 (16): 6380 .

Heiligtag, F. J., W. Cheng, V. R. de Mendonça, M. J. Süess, K. Hametner, D. Günther, C. Ribeiro, and M. Niederberger. 2014. "Self-Assembly of Metal and Metal Oxide Nanoparticles and Nanowires into a Macroscopic Ternary Aerogel Monolith with Tailored Photocatalytic Properties." Chemistry of Materials 26 (19): 5576-5584.

Jelic, A., I. Michael, A. Achilleos, E. Hapeshi, D. Lambropoulou, S. Perez, M. Petrovic, D. Fatta-Kassinos, and D. Barcelo. 2013. "Transformation Products and Reaction Pathways of Carbamazepine during Photocatalytic and Sonophotocatalytic Treatment." Journal of Hazardous Material 263 (Pt 1): 177-186. https://doi.org/10.1016/i.jhazmat.2013.07.068. 
Jimenez, S., M. M. Mico, M. Arnaldos, F. Medina, and S. Contreras. 2018. "State of the Art of Produced Water Treatment." Chemosphere 192: 186-208.

Kabra, K., C. Rubina, and R. L. Sawheny. 2004. "Treatment of Hazardous Organic and Inorganic Compounds through Aqueous-Phase Photocatalysis: A Review." Industrial and Engineering Chemistry Research 43: 7683-7696. https://doi.org/10.1021/ie0498551.

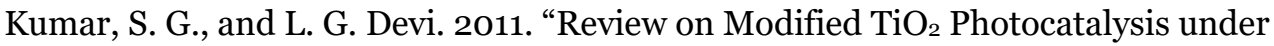
UV/Visible Light: Selected Results and Related Mechanisms on Interfacial Charge Carrier Transfer Dynamics.” Journal Physical Chemistry A 115 (46): 13211-13241.

Kwon, S., M. Fan, A. T. Cooper, and H. Yang. 2008. "Photocatalytic Applications of Micro- and Nano-TiO2 in Environmental Engineering." Critical Reviews in Environmental Science and Technology 38 (3): 197-226.

Lee, J., S. Zhang, and S. Sun. 2013. "High-Temperature Solution-Phase Syntheses of Metal-Oxide Nanocrystals." Chemistry of Materials 25 (8): 1293-1304.

Le-Minh, N., S. J. Khan, J. E. Drewes, and R. M. Stuetz. 2010. "Fate of Antibiotics during Municipal Water Recycling Treatment Processes.” Water Research 44 (15): 4295-4323.

Li, J., F. Sun, K. Gu, T. Wu, W. Zhai, W. Li, and S. Huang. 2011. "Preparation of Spindly $\mathrm{CuO}$ Micro-Particles for Photodegradation of Dye Pollutants under a Halogen Tungsten Lamp." Applied Catalysis A: General 406 (1-2): 51-58.

Li, Q., C. Gu, Y. Di, H. Yin, and J. Zhang. 2006. "Photodegradation of Nitrobenzene Using 172 nm Excimer UV Lamp." Journal of Hazardous Materials 133 (1-3): 68-74. https://doi.org/10.1016/i.jhazmat.2005.09.061.

Loeb, S. K., P. J. J. Alvarez, J. A. Brame, E. L. Cates, W. Choi, J. Crittenden, D. D. Dionysiou, Q. Li, G. Li-Puma, X. Quan, D. L. Sedlak, T. David Waite, P. Westerhoff, and J. H. Kim. 2019. "The Technology Horizon for Photocatalytic Water Treatment: Sunrise or Sunset?” Environmental Science and Technology 53 (6): 2937-2947.

Lu, F., W. Cai, Y. Zhang. 2008. “ZnO Hierarchical Micro/Nanoarchitectures: Solvothermal Synthesis and Structurally Enhanced Photocatalytic Performance.” Advanced Functional Materials 18 (7): 1047-1056. https://doi.org/10.1002/adfm.200700973.

Ma, S., R. Li, C. Lv, W. Xu, and X. Gou. 2011. "Facile Synthesis of ZnO Nanorod Arrays and Hierarchical Nanostructures for Photocatalysis and Gas Sensor Applications." Journal of Hazardous Materials 192 (2): 730-740.

Malchi, T., Y. Maor, G. Tadmor, M. Shenker, and B. Chefetz. 2014. "Irrigation of Root Vegetables with Treated Wastewater: Evaluating Uptake of Pharmaceuticals and the Associated Human Health Risks." Environmental Science and Technology 48 (16): $9325-9333$. 
Méndez-Medrano, M. G., E. Kowalska, A. Lehoux, A. Herissan, B. Ohtani, D. Bahena, V. Briois, C. Colbeau-Justin, J. L. Rodríguez-López, and H. Remita. 2016. "Surface Modification of $\mathrm{TiO} 2$ with Ag Nanoparticles and $\mathrm{CuO}$ Nanoclusters for Application in Photocatalysis." The Journal of Physical Chemistry C 120 (9): $5143-5154$.

Muñoz-Espi, R., A. Chandra, and G.Wegner. 2007. "Crystal Perfection in Zinc Oxide with Occluded Carboxyl-Functionalized Latex Particles." Crystal Growth \& Design 7 (9): 1584-1589. https://doi.org/10.1021/cg060858I.

Nolan, M., A. Iwaszuk, A. K. Lucid, J. J. Carey, and M. Fronzi. 2016. "Design of Novel Visible Light Active Photocatalyst Materials: Surface Modified $\mathrm{TiO}_{2}$." Advanced Materials 28 (27): 5425-5446.

Nosaka, Y., and A. Y. Nosaka. 2013. "Identification and Roles of the Active Species Generated on Various Photocatalysts." In Photocatalysis and Water Purification: From Fundamentals to Recent Applications, ed. P. Pichat, 3-24. Wiley VCH: Weinheim, Germany. https://doi.org/10.1002/9783527645404.ch1.

Richardson, S. D., and T. A. Ternes. 2011. "Water Analysis: Emerging Contaminants and Current Issues." Analytical Chemistry 83 (12): 4614-4648.

Robert, D., and S. Malato. 2002. "Solar Photocatalysis: A Clean Process for Water Detoxification." Science of the Total Environment 219 (1-3): 85-97. https://doi.org/10.1016/S0048-9697(01)01094-4.

Santiago-Morales, J., M. J. Gomez, S. Herrera-Lopez, A. R. Fernandez-Alba, E. GarciaCalvo, and R. Rosal. 2013. "Energy Efficiency for the Removal of Non-Polar Pollutants during Ultraviolet Irradiation, Visible Light Photocatalysis and Ozonation of a Wastewater Effluent." Water Research 47 (15): 5546-5556.

Schneider, J., M. Matsuoka, M. Takeuchi, J. Zhang, Y. Horiuchi, M. Anpo, and D. W. Bahnemann. 2014. "Understanding TiO2 Photocatalysis: Mechanisms and Materials.” Chemical Reviews 114 (19): 9919-9986.

Shaabani, B., E. Alizadeh-Gheshlaghi, Y. Azizian-Kalandaragh, and A. Khodayari. 2014. "Preparation of $\mathrm{CuO}$ Nanopowders and their Catalytic Activity in Photodegradation of Rhodamine-B." Advanced Powder Technology 25 (3): 1043-1052.

Sindelar, H. R., M. T. Brown, and T. H. Boyer. 2014. "Evaluating UV/ $\mathrm{H}_{2} \mathrm{O}_{2}$, UV/Percarbonate, and UV/Perborate for Natural Organic Matter Reduction from Alternative Water Sources." Chemosphere 105:112-118.

Ternes, T. A., A. Joss, and H. Siegrist. 2004. "Scrutinizing Pharmaceuticals and Personal Care Products in Wastewater Treatment." Environmental Science and Technology 38 (20): 394A-399A.

U.S. Environmental Protection Agency. 2012. Guidelines for Water Reuse. EPA/600/R12/618. Washington, DC: U.S. Environmental Protection Agency, Office of Wastewater Management. 
Vaseem, M., A. Umar, S. H. Kim, and Y.-B. Hahn. 2008. "Low-Temperature Synthesis of Flower-Shaped $\mathrm{CuO}$ Nanostructures by Solution Process: Formation Mechanism and Structural Properties." The Journal of Physical Chemistry C 112 (15): 57295735 .

Yan, W., H. Fan, and C. Yang. 2011. "Ultra-Fast Synthesis and Enhanced Photocatalytic Properties of Alpha- $\mathrm{Fe}_{2} \mathrm{O}_{3} / \mathrm{ZnO}$ Core-Shell Structure." Materials Letters 65 (11): 1595-1597.

Yan, X., K. Yuan, N. Lu, H. Xu, S. Zhang, N. Takeuchi, H. Kobayashi, and R. Li. 2017. "The Interplay of Sulfur Doping and Surface Hydroxyl in Band Gap Engineering: Mesoporous Sulfur-Doped $\mathrm{TiO}_{2}$ Coupled with Magnetite as a Recyclable, Efficient, Visible Light Active Photocatalyst for Water Purification.” Applied Catalysis B: Environmental 218: 20-31.

Yao, W., S. W. Ur Rehman, H. Wang, H. Yang, G. Yu, and Y. Wang. 2018. "Pilot-Scale Evaluation of Micropollutant Abatements by Conventional Ozonation, $\mathrm{UV} / \mathrm{O}_{3}$, and an Electro-Peroxone Process." Water Research 138:106-117. https://doi.org/10.1016/i.watres.2018.03.044.

Yin, Q. Q., W. J. Wu, R. Qiao, X. X. Ke, Y. Hu, and Z. Q. Li. 2016. "Glucose-Assisted Transformation of Ni-doped-ZnO@carbon to a Ni-Doped-ZnO@void@ $\mathrm{SiO}_{2}$ CoreShell Nanocomposite Photocatalyst." RSC Advances 6 (45): 38653-38661.

Yu, J., G. Dai, and B. Huang. 2009. "Fabrication and Characterization of Visible-LightDriven Plasmonic Photocatalyst $\mathrm{Ag} / \mathrm{AgCl} / \mathrm{TiO}_{2}$ Nanotube Arrays.” The Journal of Physical Chemistry C 113 (37): 16394-16401.

Zhou, H., and S. S. Wong. 2008. "A Facile and Mild Synthesis of 1-D ZnO, CuO, and $\alpha-$ $\mathrm{Fe}_{2} \mathrm{O}_{2}$ Nanostructures and Nanostructured Arrays.” ACS Nano 2 (5): 944-958. 


\section{Appendix A: Mass Spectra of Contaminants and Byproducts}

Figure A-1. Mass spectra of methyl orange in (a) negative and $(b)$ positive ion modes, and mass spectra of $(c)$ carbamazepine in negative ion mode.

(a)

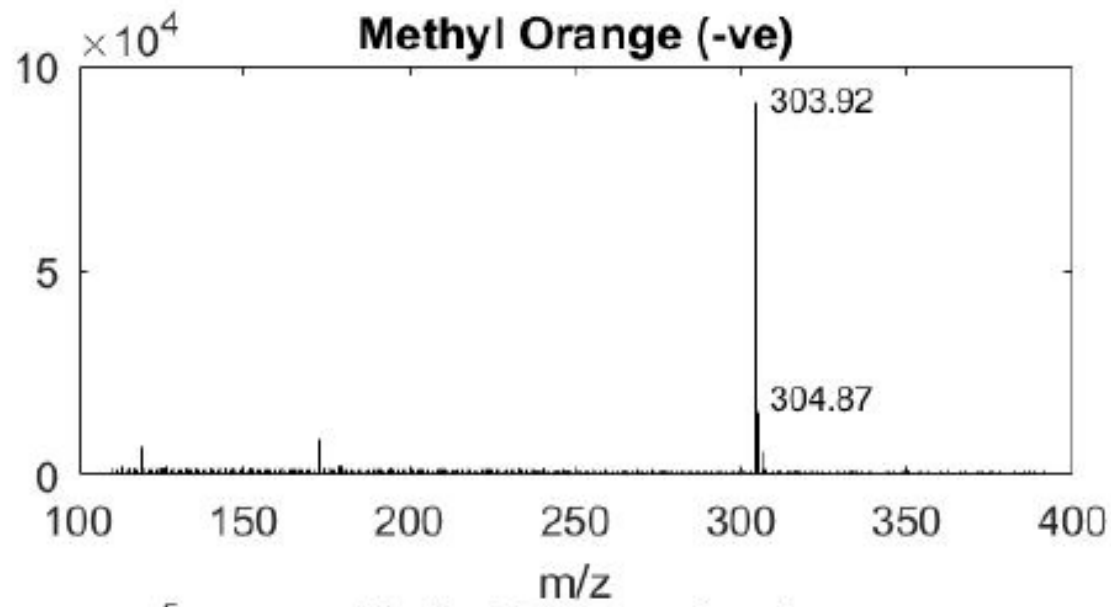

(b) $\times 10^{5}, \quad$ Methyl Orange (+ve)

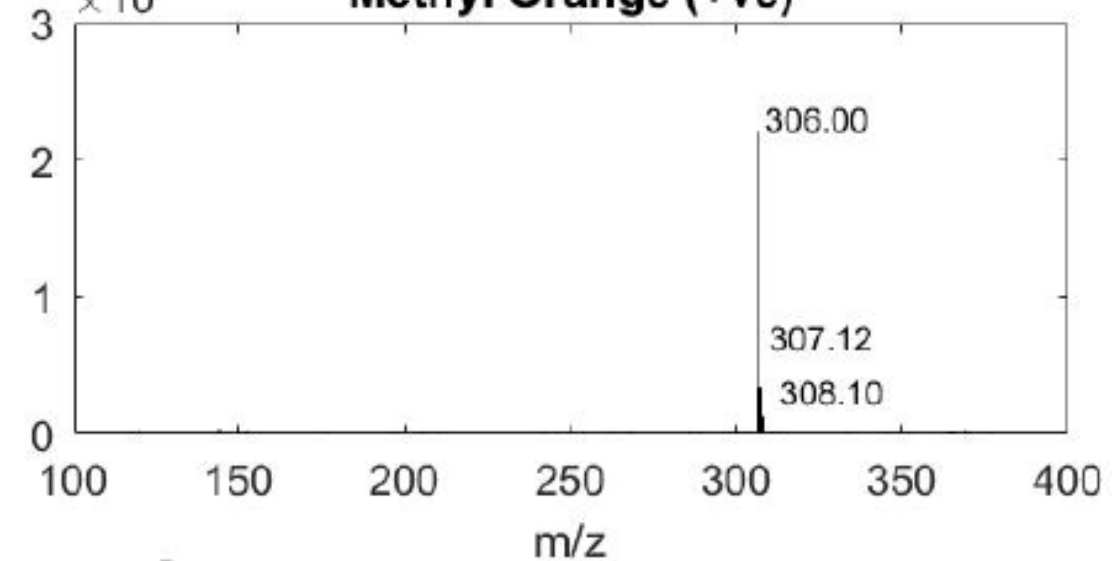

(c) $15 \times 10^{5}, \quad$ Carbamazepine (+ve)

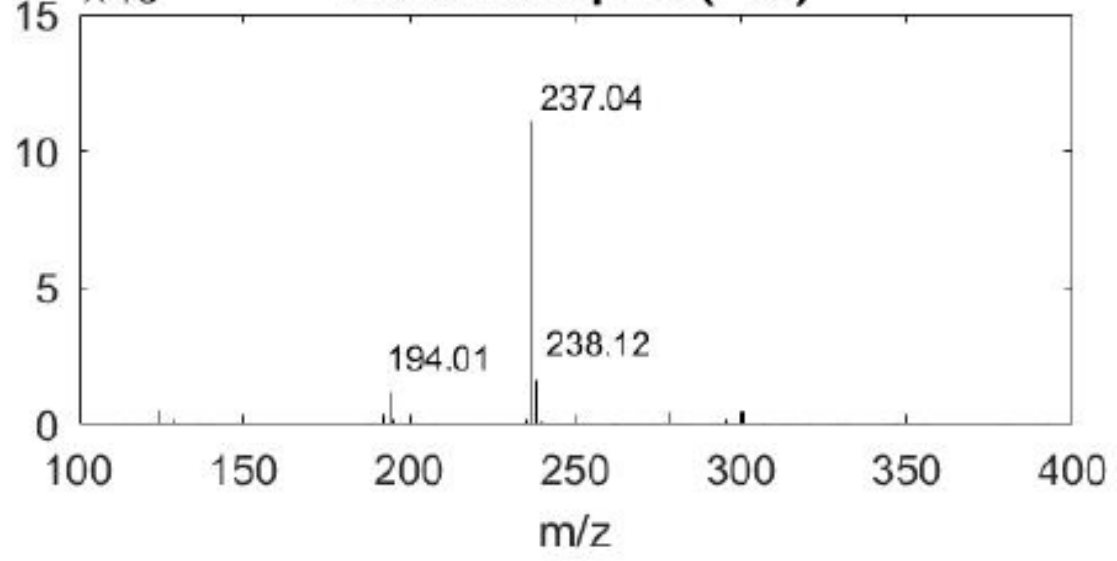


Figure A-2. Mass spectra of methyl orange products $(a) \mathrm{B},(b) \mathrm{C},(c) \mathrm{A}$ and $(d)$ carbamazepine product.

(a)

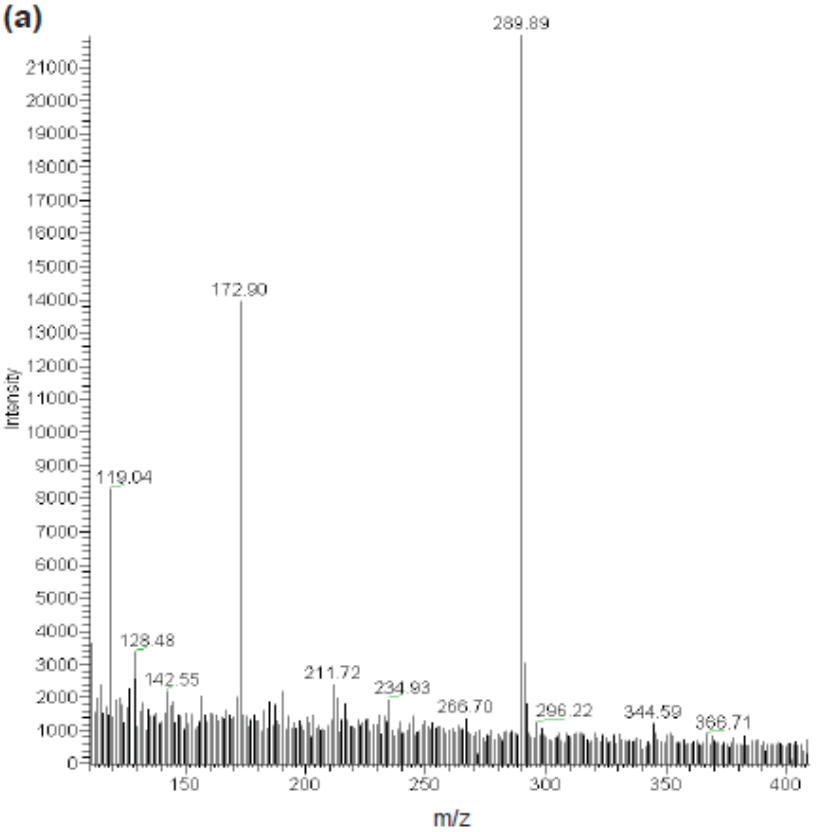

(c)

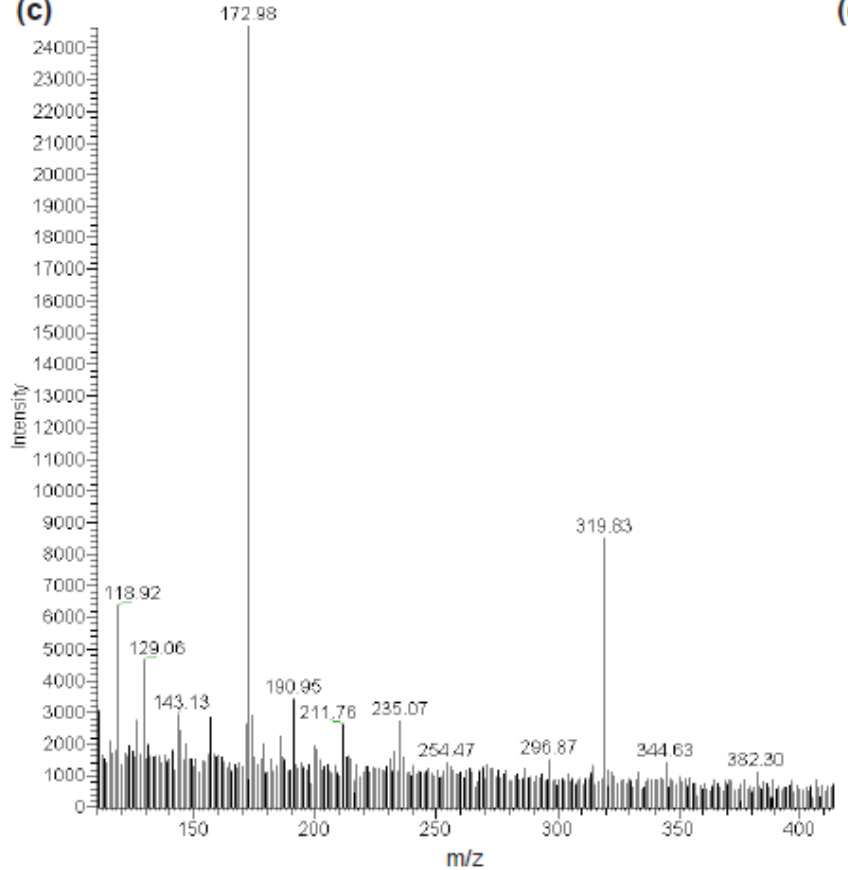

(b)

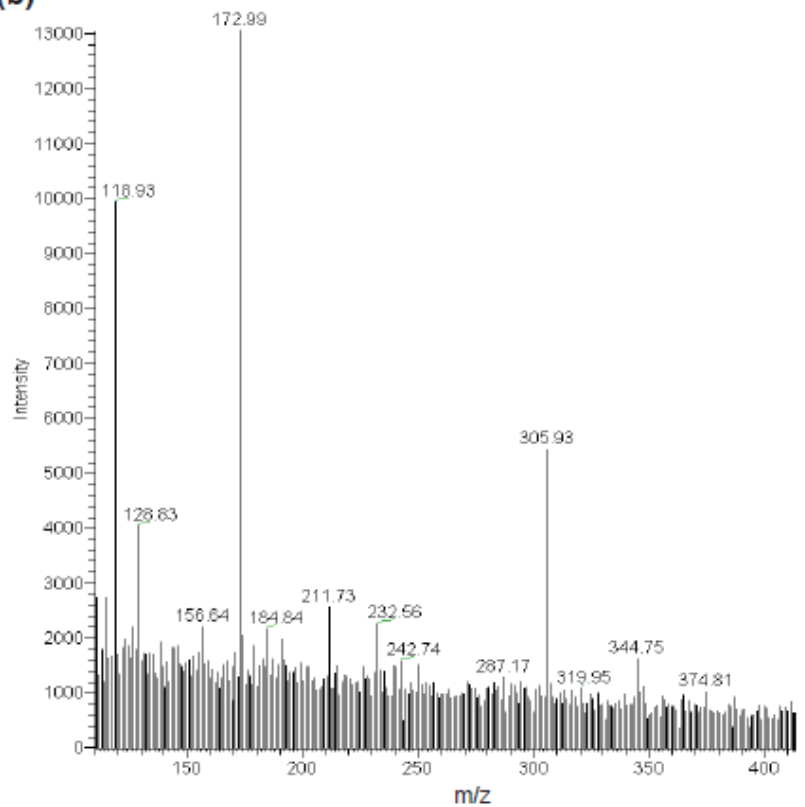

(d)

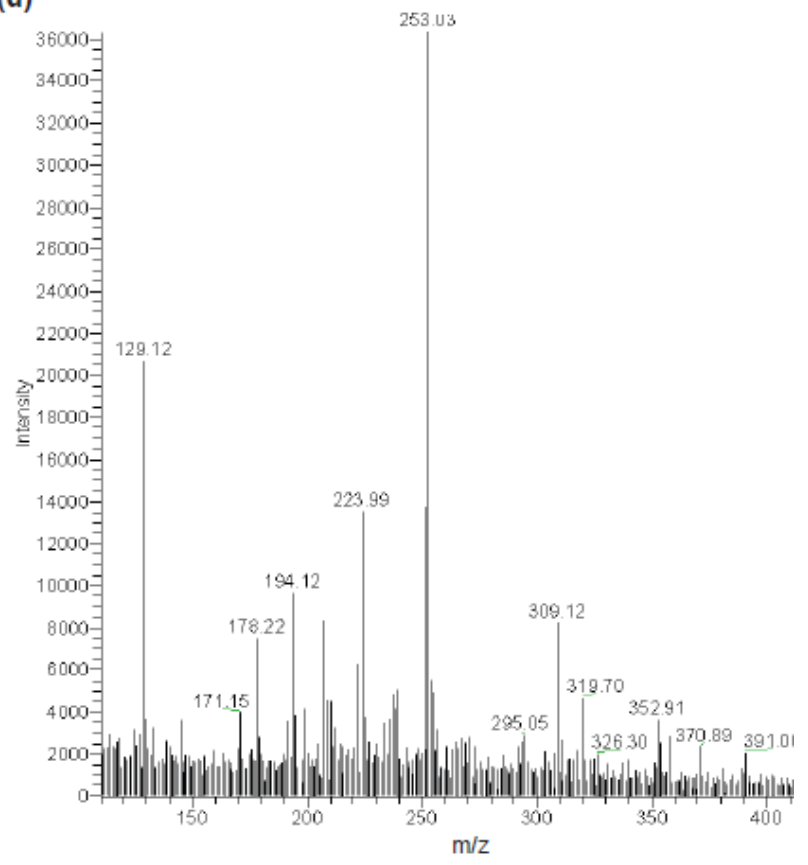




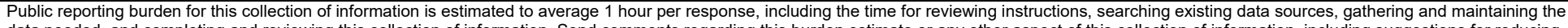

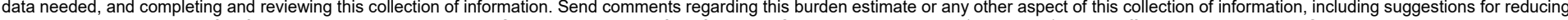

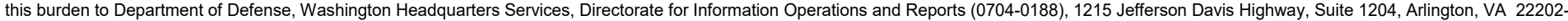

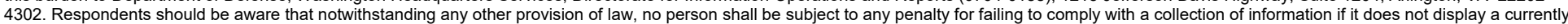
valid OMB control number. PLEASE DO NOT RETURN YOUR FORM TO THE ABOVE ADDRESS

\section{\begin{tabular}{l|l} 
valid OMB control number. PLEASE DO NOT RETURN YOUR FORM TO THE ABOVE ADDRESS. \\
\hline 1. REPORT DATE (DD-MM-YYYY)
\end{tabular}}

July 2020

\section{TITLE AND SUBTITLE}

High-Performance Photocatalytic Degradation of Model Contaminants with Iron Oxide-Based Colloidal

Solutions under Broad-Spectrum Illumination

\section{AUTHOR(S)}

Emma K. Ambrogi, Emily Asenath-Smith, and Jonathon A. Brame

\section{DATES COVERED (From - To)} FY16-FY19

5a. CONTRACT NUMBER

\section{5b. GRANT NUMBER}

\section{5c. PROGRAM ELEMENT}

622720048

5d. PROJECT NUMBER

5e. TASK NUMBER

5f. WORK UNIT NUMBER

8. PERFORMING ORGANIZATION REPORT NUMBER

ERDC TR-20-14

U.S. Army Engineer Research and Development Center (ERDC)

Environmental Laboratory (EL)

Waterways Experiment Station

3909 Halls Ferry Road

Vicksburg, MS 39180-6199
Laboratory (CRREL)

72 Lyme Road

Hanover, NH 03755-1290

\section{(S) AND ADDRESS(ES)}

Headquarters, U.S. Army Corps of Engineers

Washington, DC 20314-1000

10. SPONSOR/MONITOR'S ACRONYM(S) USACE

11. SPONSOR/MONITOR'S REPORT NUMBER(S)

\section{DISTRIBUTION / AVAILABILITY STATEMENT}

Approved for public release; distribution is unlimited.

\section{SUPPLEMENTARY NOTES}

ERDC 6.2 Advanced Low Logistics Water (ALL-H2O)

\section{ABSTRACT}

Small molecule contaminants, such as compounds from pharmaceuticals, personal care products, and pesticides, persist through traditional wastewater treatment processes. Heterogeneous photocatalysis with transition metal oxides (TMOs) is an emerging technology for removing these recalcitrant contaminants from wastewater. To leverage this technology, we selectively combined three different TMOs with bandgap energies in different regions of the solar spectrum as a means of harvesting multiple wavelengths of incident radiation to increase the degradation rate of model and real contaminants. Specifically, we combined zincite (ZnO, ultraviolet active), hematite ( $\alpha$ $\mathrm{Fe}_{2} \mathrm{O}_{3}$, visible active), and tenorite (CuO, near-infrared active). The combination of tenorite and hematite (2:1 mass ratio) was the most effective, degrading methyl orange with a rate constant of $40 \pm 1 \mathrm{E}-03 \mathrm{~min}^{-1}$.

When applied to multicontaminant solutions using laboratory illumination, our multispectral photocatalyst degrades real-world contaminants, methyl orange, carbamazepine, and nitrobenzene, with rate constants of $30 \pm 1 \mathrm{E}-03,24 \pm 1 \mathrm{E}-03$, and $6 \pm 1 \mathrm{E}-03 \mathrm{~min}{ }^{-1}$, respectively. In addition, the material degrades contaminants with a greater efficiency under outdoor solar illumination, with Collector Area per Order values of 4.0, 6.1 and $14.5 \mathrm{kWh} /$ order $/ \mathrm{m}^{3}$, for methyl orange, carbamazepine, and nitrobenzene, respectively. These results demonstrate the effectiveness of this approach to purify water for strategic applications.

\section{SUBJECT TERMS}

Persistent pollutants, Photocatalysis--Evaluation, Transition metal oxides, Water--Pollution, Water--Purification--Photocatalysis

16. SECURITY CLASSIFICATION OF:
\begin{tabular}{|c|c|c|}
\hline $\begin{array}{c}\text { a. REPORT } \\
\text { Unclassified }\end{array}$ & $\begin{array}{c}\text { b. ABSTRACT } \\
\text { Unclassified }\end{array}$ & $\begin{array}{c}\text { c. THIS PAGE } \\
\text { Unclassified }\end{array}$ \\
\hline
\end{tabular}

\begin{tabular}{|c|c|c|}
\hline $\begin{array}{c}\text { 17. LIMITATION } \\
\text { OF ABSTRACT }\end{array}$ & $\begin{array}{c}\text { 18. NUMBER } \\
\text { OF PAGES }\end{array}$ & $\begin{array}{c}\text { 19a. NAME OF RESPONSIBLE PERSON } \\
\text { SAR }\end{array}$ \\
\cline { 3 - 3 } & 38 & $\begin{array}{c}\text { 19b. TELEPHONE NUMBER } \\
\text { (include area code) }\end{array}$ \\
\hline
\end{tabular}

